OPEN ACCESS

Edited by:

Andrei Mocan,

Iuliu Haţieganu University of Medicine and Pharmacy, Romania

Reviewed by:

Ligia Salgueiro,

University of Coimbra, Portugal

Lu Yan,

Jiangsu Province and Chinese Academy of Sciences, China

*Correspondence:

Zheng Zhou

zhouzheng037@163.com

Chunsheng Zhu

zhuchunsheng6@163.com

${ }^{t}$ These authors have contributed equally to this work and share first authorship

Specialty section: This article was submitted to

Ethnopharmacology,

a section of the journal

Frontiers in Pharmacology

Received: 16 October 2019

Accepted: 18 August 2020

Published: 15 September 2020

Citation:

Nie A, Chao Y, Zhang X, Jia W, Zhou Z and Zhu C (2020) Phytochemistry and

Pharmacological Activities of Wolfiporia cocos (F.A.

Wolf) Ryvarden \& Gillb.

Front. Pharmacol. 11:505249. doi: 10.3389/fphar.2020.505249

\section{Phytochemistry and Pharmacological Activities of Wolfiporia cocos (F.A. Wolf) Ryvarden \& Gilb}

\author{
Anzheng $\mathrm{Nie}^{1+}$, Yanhui $\mathrm{Chao}^{2 \dagger}$, Xiaochuan Zhang ${ }^{1}$, Wenrui Jia ${ }^{1}$, Zheng Zhou ${ }^{1 *}$ \\ and Chunsheng Zhu ${ }^{1 *}$
}

${ }^{1}$ Department of Chinese Medicine, The First Affiliated Hospital of Zhengzhou University, Zhengzhou, China, ${ }^{2}$ Department of Pharmacy, The First Affiliated Hospital of Zhengzhou University, Zhengzhou, China

Poria cocos is the dried sclerotium of Wolfiporia cocos (F.A. Wolf) Ryvarden \& Gillb., which was the current accepted name and was formerly known as Macrohyporia cocos (Schwein.) I. Johans. \& Ryvarden, Pachyma cocos (Schwein.) Fr., Poria cocos F.A. Wolf and Sclerotium cocos Schwein. It is one of the most important crude drugs in traditional Chinese medicine, with a wide range of applications in ameliorating phlegm and edema, relieving nephrosis and chronic gastritis and improving uneasiness of minds. Its extensive pharmacological effects have attracted considerable attention in recent years. However, there is no systematic review focusing on the chemical compounds and pharmacological activities of Poria cocos. Therefore, this review aimed to provide the latest information on the chemical compounds and pharmacological effects of Poria cocos, exploring the therapeutic potential of these compounds. We obtained the information of Poria cocos from electronic databases such as SCl finder, PubMed, Web of Science, CNKI, WanFang DATA and Google Scholar. Up to now, two main active ingredients, triterpenes and polysaccharides of Poria cocos, have been identified from Poria cocos. It has been reported that they have pharmacological effects on anti-tumor, anti-bacterial, anti-oxidant, anti-inflammatory, immunomodulation, and liver and kidney protection. The review summarizes the phytochemistry and pharmacological properties of Poria cocos, which suggest that researchers should focus on the development of new drugs about Poria cocos to make them exert greater therapeutic potential.

Keywords: Wolfiporia cocos (F.A. Wolf) Ryvarden \& Gilb., phytochemistry, traditional uses, pharmacology, anti-tumor

\section{INTRODUCTION}

Poria cocos is the dried sclerotia of Wolfiporia cocos (F.A. Wolf) Ryvarden \& Gilb., which is also referred to as "Fuling" in China (Yuan et al., 2018; Royal Botanical Gardens at Kew, 2020; Wang et al., 2020). It is a health-care edible medicinal mushroom belonging to family Polyporaceae and is firstly recorded in an ancient Chinese medical masterpiece "Sheng Nong's herbal classic" that has been used as famous traditional Chinese medicine for over 2,000 years (Li X. et al., 2019) (Figure 1). Poria cocos grows underground on the colonization of Pinus species (Yang et al., 2019) and is 


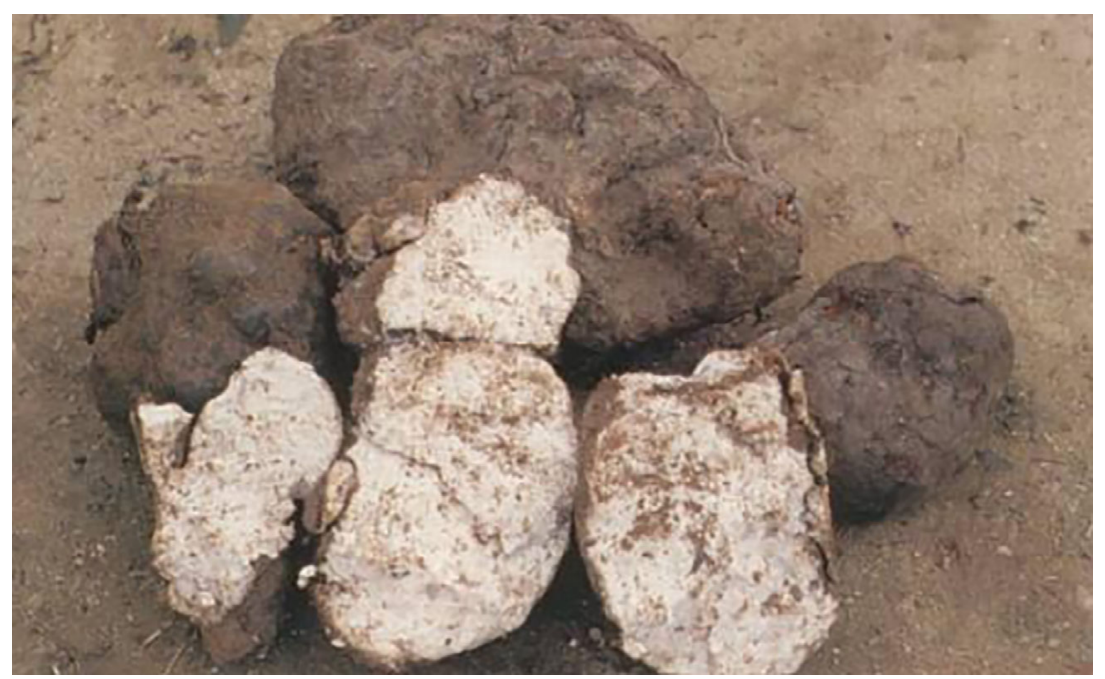

FIGURE 1 | The fruiting body of Mushroom Poria cocos. Poria cocos has been used as famous traditional Chinese medicine known as "Fuling" in Chinese for over 2000 of years.

extensively used in China as well as other East Asian countries for its various the rapeutic effects. Its clinical indications include promoting urination, removing dampness, invigorating the spleen, and calming the nerves (Kobira et al., 2012; Li et al., 2012; Wang et al., 2012a). Owning to its markedly medicinal function, few side effects and rich resources, the phytochemistry and pharmacology properties of Poria cocos have become a hot topic since the 1960s. Furthermore, previous studies have also showed that the chemical components of Poria cocos includ triterpenes, polysaccharides, and other minor components such as steroids, amino acids, and so on (Sun, 2014). According to the existing research literature, it can be clearly seen that the main active constituents of Poria cocos are concentrated on triterpenes and polysaccharides (Jia et al., 2016). Some of these constituents possessed a series of biological activities including anti-tumor (Sun and Xia, 2018), hepatoprotective (Wu et al., 2019), antiinflammatory (Lee et al., 2017), anti-oxidant (Wang et al., 2016), anti-bacterial (Wang et al., 2019a), immunomodulation(Pu et al., 2019), etc. Therefore, these complex chemical compounds and pharmacological effects of Poria cocos attracted researcher's considerable attention, meanwhile, they also brought huge challenges for research.

The objectives of the review are i) to summarize the chemical compounds and pharmacological effects of Poria cocos, ii) to update the latest published data about Poria cocos, and iii) to discuss some promising direction for further research on Poria cocos.

\section{ETHNOBOTANICAL STUDIES}

Poria cocos is mainly native to East Asia and Southeast Asia and concentrated in regions with a subtropical and humid climate such as China, Vietnam, and Thailand. Poria cocos is a geographically representative product of Yunnan and Anhui in Hubei Province. Luotian County in Hubei Province was once approved the Good Agricultural Practice (GAP) planting demonstration base of Poria cocos (Rios, 2011).

Compatible with other Chinese medicines, Poria cocos can be usually formulated to ameliorate a variety of syndromes but is generally not used alone. First described in a classic prescription book, Jin Kui Yao Lue (金贵要略), Dang Gui Shao Yao San can be frequently applied in the treatment of anemia and ocular disorders and Poria cocos of this formula is used to eliminate damp and strengthen spleen (Shen et al., 2005). Another farmous formula, Gui Zhi Fu Ling Wan, which was also recorded in Jin Kui Yao Lue (金贵 要略), can effectively promote blood circulation or removing stasis (Nozaki et al., 2014). In Gui Zhi Fu Ling Wan, Poria cocos has a similar effect such as resolving dampness and tonifying spleen as in Dang Gui Shao Yao San. Another classic formula containing Poria cocos is Wu Ling San, of which Poria cocos plays an irreplaceable role to clear out edemas induced by nephropathy, diabetes, and brain damage. Besides, there are other formulas containing Poria cocos, such as Si Jun Zi Tang recorded in the Tai Ping Hui Min He Jue Fang (太平惠民和剂局方), Zhu Ling Tang and Ling Gui Zhu Gan Tang both of which are documented in the Shang Han Lun (伤 寒论) (Hsu et al., 1996). In the Chinese pharmacopoeia 2015 edition, the traditional Chinese medicine preparations containing Poria cocos accounted for nearly 15\% (Zhu et al., 2018a). In conclusion, Poria cocos has generated irreplaceable effects in many prescriptions.

\section{MODERN QUALITY CONTROL}

Poria cocos contains two main bioactive components, the triterpene acids and the polysaccharide fraction. Triterpenes, 
however, are generally regarded as the principal groups of chemicals of Poria cocos and often selected as the chemical markers to evaluate the quality of Poria cocos (Rios, 2011; Zhu et al., 2018b). Moreover, pachymic acid is specific to Poria cocos and do not exist in any other traditional Chinese medicine. In China, the quality of Poria cocos produced in Yunnan is the best. Many effective and credible methods including high performance liquid chromatography (HPLC), liquid chromatography (LC), liquid chromatography coupled with mass spectrometry (LCMS), and DNA sequencing analysis to isolate and identify the active ingredients had been applied for the quality control of Poria cocos (Zhu et al., 2018a). Ultra-performance liquid chromatography-quadrupole/time- of-flight mass spectrometry (UHPLC-QTOF-MS/MS) was used to explore the differences of secondary metabolites in these three botanical parts (the epidermis, middle, and inner part) of Poria cocos. Fifteen chemical components which were common to all three parts, were unequivocally or tentatively identified and eight major bioactive triterpene acids were simultaneously quantified for quality evaluation (Zhu et al., 2018b). Ten compounds were screened out as potential markers to distinguish the quality of Poria cocos by UHPLC-QTOF-MS/MS (Zhu et al., 2018a).

\section{CONSTITUENTS FROM PORIA COCOS}

\section{Triterpenes}

In the past decades, a total of 91 triterpenes, 1-91, were isolated and identified from Poria cocos and ascribed to derivations of lanostane or secolanostane skeletons (Table 1 and Figures 2-6).

\section{Polysaccharides}

Poria cocos polysaccharide (PCP) was extracted from the dried sclerotium of Poria cocos (84\%, w/w), (Li X. et al., 2019) (Table 2). Different crude polysaccharide fractions were isolated by different solvent extraction methods, such as PCM1 (0.9\% NaCl), PCM2 (hot water), PCSIII-2 (0.5 mol/L NaOH), PCM0 (MeOH), and PCP4-II (88\% formic acid) (Wang et al., 2004a). Hence, PCP is undoubtedly a mixture of various types of polysaccharides, which consist of galactose, fucose, mannose, arabinose, xylose and glucose. $\beta$-glucan is regarded as the principal polysaccharide in Poria cocos with a $(1 \rightarrow 3)$-linked glucose backbone main chain and some $(1 \rightarrow 6)$-linked glucose side chains as shown in Figure 7 (Jin et al., 2003a). To increase the water solubility of PCP, the side chains of the $\beta$-glucan was removed through the chemical reaction of periodate oxidation and smith degradation and the final product was named as "pachymaran" (Chihara et al., 1970). By carboxymethylation, the solubility and biological activity of PCP were further improved. Meanwhile, many chemical reactions including sulfation, carboxymethylation plus sulfation, methylation, hydroxpropylation, and hydroxyethylation have been also performed and these modified derivatives were also studied (Wang et al., 2004b; Huang and Zhang, 2005; Chen et al., 2010; Wang et al., 2012b). In general, these derivatives possessed better water-solubility performance and enhanced pharmacological activities.

\section{PHARMACOLOGICAL ACTIVITIES AND TOXICOLOGICAL INFORMATION}

Many experts and scholars have revealed that Poria cocos possessed remarkable pharmacological effects and complex mechanisms both in vitro and in vivo, as shown in Table 3.

\section{Anti-Tumor Effects}

One anticancer mechanism of PCP seemed to be related to the stimulation of cell-mediated immune responses (Lin and Zhang, 2004; Ke et al., 2010) (Figure 8). In 1983, a polysaccharide H11 with anti-cancer effects was firstly isolated from Poria cocos. Experiments demonstrated that $\mathrm{H} 11$ (4 and $8 \mathrm{mg} \cdot \mathrm{kg}^{-1}$ ) had significant inhibition activity against subcutaneous mouse sarcoma S180 with inhibition ratio 94 and 96\% respectively but no inhibition activity against ascites S180. H11 appeared to act through a host-mediated pathway rather than blocking tumor growth directly (Kanayama et al., 1983; Kanayama et al., 1986). Thirty and $100 \mu \mathrm{g} \cdot \mathrm{ml}^{-1} \mathrm{PCSC}$, a PCP, could promote the production of NO (nitric oxide) and induce the transcription of iNOS (NO synthase) in RAW 264.7 macrophage cells by the activation of nuclear factor $\mathrm{kB} / \mathrm{Rel}(\mathrm{NF}-\mathrm{kB} / \mathrm{Rel}$ ) pathway. Specifically, NF-kB/Rel pathway could be activated through strengthening the phosphorylation of $\mathrm{IkB}$ and $\mathrm{p} 38$ kinase. Moreover, NF-kB/Rel might translocate into the nucleus and bind to the promoter of iNOS gene (Lee et al., 2004). Three polysaccharides (Pi-PCM0, Pi-PCM1, and Pi-PCM2) derived from Poria cocos, all showed significant anti-proliferation effects on S-180 tumor-bearing BALB/c mice in vivo and on HL-60 tumor cell in vitro (Huang et al., 2007). After treating the breast cancer cells for $72 \mathrm{~h}$ with $12.5-400 \mu \mathrm{g} \cdot \mathrm{ml}^{-1}$ of watersoluble $\beta$-glucan PCM3-II extracted from Poria cocos, the proliferation and viability of the MCF-7 cells was reduced dose-dependently and the cell-cycle G1 arrest was induced time-dependently. Mechanistically, the arrest was related with the down-regulations of unscheduled cyclin D1 and cyclin E expression. And increasing the ratio of Bax (pro-apoptosis)/Bcl-2 (anti-apoptosis) in breast cancer cells could induce apoptosis (Zhang et al., 2006).

Jin et al. found that the PCP cultured from wild strain in the medium containing corn steep liquor had the highest anti-tumor activity against S-180 in vivo, while the PCP cultured from cultivated strain in the medium containing bran extract had no obvious inhibitiory effects on tumor growth. studies on ac-PCM2 and wc-PCM2 showed that the higher molecular mass and better water solubility the polysaccharide possessed, the stronger the anti-tumor potency (Jin et al., 2003a). In BALB/c mice, the antitumor activity against S-180 of CS-PCS3-II, a derivative of PCS3II, was markedly higher than that of PCS3-II. Histological examination showed that the S-180 tumor cells administrated with CS-PCS3-II appeared necrosis and even apoptosis, and the immunological responses in mice was enhanced (Chen et al., 2010). Compared with the native non-sulfated Pi-PCM3-I, sulfated derivatives (S1-S6) showed markedly higher antitumor activity against S-180 in mice and HepG2 and S-180 tumor cells, but lower toxicity was observed than 5-fluorouracil. 
TABLE 1 | Summary of the Lanosta-8-ene type triterpenes in Poria cocos.

\begin{tabular}{|c|c|c|c|}
\hline S.N. & Origins & Compounds & Reference \\
\hline \multicolumn{4}{|c|}{ Lanosta-8-ene type triterpenes } \\
\hline 1 & Surface layer, Sclerotium & Pachymic acid & (Fu et al., 2018) \\
\hline 2 & Sclerotium & Tumulosic acid & (Lv et al., 2013) \\
\hline 3 & Surface layer & Eburicoic acid & (Huang et al., 2018) \\
\hline 4 & Sclerotium & 3-O-acetyl-16 $\alpha$-hydroxytrametenolic acid & (Wang et al., 2013) \\
\hline 5 & Sclerotium & $16 \alpha$-Hydroxytrametenolic acid & (Wang et al., 2013) \\
\hline 6 & Surface layer & Trametenolic acid & (Li et al., 2017) \\
\hline 7 & Sclerotium & 25-Hydroxypachymic acid & (Zheng and Yang, 2008a) \\
\hline 8 & Surface layer & 25-Hydroxy-3-epitumulosic acid & (Akihisa et al., 2009) \\
\hline 9 & Surface layer & $16 \alpha$-Hydroxyeburiconic acid & (Wang et al., 2013) \\
\hline 10 & Surface layer & $16 \alpha, 25$-Dihydroxyeburiconic acid & (Akihisa et al., 2009) \\
\hline 11 & Surface layer & Eburicoic acid acetate & (Lee et al., 2018a) \\
\hline 12 & Surface layer & Versisponic acid E & (Chen B. et al., 2019) \\
\hline 13 & Surface layer & Pinicolic acid A & (Chen B. et al., 2019) \\
\hline 14 & Surface layer & Pinicolic acid E & (Chen B. et al., 2019) \\
\hline \multicolumn{4}{|c|}{ Lanosta-7,9(11)-diene type triterpenes } \\
\hline 15 & Sclerotium & 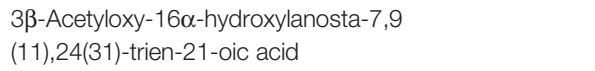 & (Shingu et al., 1992) \\
\hline 16 & Sclerotium & 29-Hydroxydehydrotumulosic acid & (Cai and Cai, 2011) \\
\hline 17 & Sclerotium & 29-Hydroxydehydropachymic acid & (Cai and Cai, 2011) \\
\hline 18 & Sclerotium & $16 \alpha$-Hydroxydehydropachymic acid & (Nukaya et al., 1996) \\
\hline 19 & Surface layer & Dehydroeburicoic acid monoacetate & (Lee et al., 2018b) \\
\hline 20 & Sclerotium & $\begin{array}{l}\text { 3-O-acetyl-16 } \alpha- \\
\text { hydroxydehydrotrametenolic acid }\end{array}$ & (Zeng et al., 2015) \\
\hline 21 & Surface layer, Sclerotium & Dehydrotrametenolic acid & (Qian et al., 2018) \\
\hline 22 & Sclerotium & $\begin{array}{l}3 \beta, 16 \alpha \text {-Dihydroxylanosta-7,9(11),24- } \\
\text { trien-21-oic acid }\end{array}$ & (Zeng et al., 2015) \\
\hline 23 & Surface layer & Dehydrotrametenonic acid & (Akihisa et al., 2007) \\
\hline 24 & Surface layer & 3ß-(Acetyloxy)lanosta-7,9(11),24-trien-21-oic acid & (Chen B. et al., 2019) \\
\hline 25 & Surface layer, Sclerotium & 3-epi-Dehydrotrametenolic acid & (Akihisa et al., 2007; Yang C. et al., 2010) \\
\hline 26 & Surface layer & 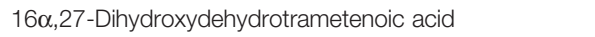 & (Akihisa et al., 2009) \\
\hline 27 & Surface layer & 3,15-O-diacetyl-dehydrotrametenolic acid & (Chihara et al., 1970) \\
\hline 28 & Surface layer & $16 \alpha$-Hydroxy-3-oxolanosta-7,9(11),24-trien-21-oic acid & (Chen B. et al., 2019) \\
\hline 29 & Surface layer & 3-epi-Dehydrotumulosic acid & (Wu et al., 2016a) \\
\hline 30 & Surface layer, Sclerotium & 25-Hydroxy-3-epidehydrotumulosic acid & (Ukiya et al., 2002) \\
\hline 31 & Surface layer & Dehydrosulphurenic acid & (Peng et al., 2017) \\
\hline 32 & Surface layer & Coriacoic acid B & (Chen B. et al., 2019) \\
\hline 33 & Surface layer, Sclerotium & Dehydropachymic acid & (Jin et al., 2019) \\
\hline 34 & Sclerotium & 3-epi-Dehydropachymic acid & (Zhou et al., 2008) \\
\hline 35 & Surface layer, Sclerotium & Dehydrotumulosic acid & (Ji et al., 2018) \\
\hline 36 & Sclerotium & 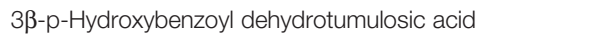 & (Yasukawa et al., 1998) \\
\hline 37 & Surface layer & $15 \alpha$-Hydroxydehydrotumulosic acid & (Zan et al., 2017) \\
\hline 38 & Surface layer & Dehydroeburicoic acid & (Eom et al., 2018) \\
\hline 39 & Surface layer & Poriacosone A & (Zheng and Yang, 2008a) \\
\hline 40 & Sclerotium & Polyporenic acid C & (Cheng et al., 2019) \\
\hline 41 & Surface layer & Dehydroeburiconic acid & (Lee et al., 2009) \\
\hline 42 & Sclerotium & Poriacosone B & (Zheng and Yang, 2008a) \\
\hline 43 & Surface layer & $16 \alpha, 25$-Dihydroxydehydroeburiconic acid & (Akihisa et al., 2007) \\
\hline 44 & Sclerotium & 29-Hydroxypolyporenic acid C & (Cai and Cai, 2011) \\
\hline 45 & Sclerotium & $6 \alpha$-Hydroxypolyporenic acid C & (Zheng and Yang, 2008b) \\
\hline 46 & Surface layer & Porilactone A & (Chen B. et al., 2019) \\
\hline 47 & Surface layer & Porilactone B & (Chen B. et al., 2019) \\
\hline 48 & Surface layer & Pinicolic acid F & (Chen B. et al., 2019) \\
\hline 49 & Surface layer & Poricoic acid ZL & (Chen L. et al., 2019) \\
\hline 50 & Surface layer & Poricoic acid ZI & (Chen L. et al., 2019) \\
\hline \multicolumn{4}{|c|}{ 3,4-seco-lanostan-8-ene type triterpenes } \\
\hline 51 & Surface layer & 25-Hydroxyporicoic acid H & (Akihisa et al., 2007) \\
\hline 52 & Surface layer & Poricoic acid $\mathrm{H}$ & (Ukiya et al., 2002) \\
\hline 53 & Surface layer & Poricoic acid HM & (Akihisa et al., 2009) \\
\hline 54 & Surface layer & Poricoic acid G & (Ukiya et al., 2002) \\
\hline 55 & Surface layer & Poricoic acid GM & (Akihisa et al., 2009) \\
\hline 56 & Surface layer & Poricoic acid ZK & (Chen B. et al., 2019) \\
\hline 57 & Surface layer & Poricoic acid ZA & (Wang et al., 2017) \\
\hline
\end{tabular}


TABLE 1 | Continued

\begin{tabular}{|c|c|c|c|}
\hline S.N. & Origins & Compounds & Referen \\
\hline \multicolumn{4}{|c|}{ 3,4-seco-lanostan-7,9(11)-diene type triterpenes } \\
\hline 58 & Surface layer & Poricoic acid E & (Wang H. et al., 2015) \\
\hline 59 & Surface layer & Poricoic acid BM & (Tai et al., 1995) \\
\hline 60 & Surface layer, Sclerotium & Poricoic acid B & (Dong et al., 2015) \\
\hline 61 & Surface layer & Poricoic acid I & (Chen B. et al., 2019) \\
\hline 62 & Surface layer & Poricoic acid J & (Chen B. et al., 2019) \\
\hline 63 & Surface layer & Poricoic acid JM & (Chen B. et al., 2019) \\
\hline 64 & Surface layer & 16-Deoxyporicoic acid BM & (Chen B. et al., 2019) \\
\hline 65 & Surface layer, Sclerotium & 16-Deoxyporicoic acid B & (Akihisa et al., 2007) \\
\hline 66 & Sclerotium & $\begin{array}{l}\text { 3,4-seco-lanosta-4(28),7,9,24Z-tetraen- } \\
\text { 3,26-dioic acid }\end{array}$ & (Yang L. et al., 2010) \\
\hline 67 & Surface layer & Poricoic acid $\mathrm{K}$ & (Chen B. et al., 2019) \\
\hline 68 & Surface layer & Poricoic acid L & (Chen B. et al., 2019) \\
\hline 69 & Surface layer & Poricoic acid M & (Chen B. et al., 2019) \\
\hline 70 & Surface layer & Poricoic acid $\mathrm{N}$ & (Chen B. et al., 2019) \\
\hline 71 & Surface layer & Poricoic acid $O$ & (Chen B. et al., 2019) \\
\hline 72 & Surface layer & Poricoic acid F & (Tai et al., 1995) \\
\hline 73 & Surface layer, Sclerotium & Poricoic acid A & (Qian et al., 2018) \\
\hline 74 & Surface layer & Poricoic acid CM & (Akihisa et al., 2007) \\
\hline 75 & Surface layer & Poricoic acid C & (Qian et al., 2018) \\
\hline 76 & Surface layer & Poricoic acid AM & (Zhang W. et al., 2019) \\
\hline 77 & Surface layer & Poricoic acid $\mathrm{AE}$ & (Yang C. et al., 2010) \\
\hline 78 & Surface layer & Poricoic acid CE & (Yang C. et al., 2010) \\
\hline 79 & Surface layer & Poricoic acid D & (Zhang G. et al., 2019) \\
\hline 80 & Surface layer & Poricoic acid DM & (Akihisa et al., 2009) \\
\hline 81 & Surface layer & 25-Methoxyporicoic acid A & (Akihisa et al., 2009) \\
\hline 82 & Surface layer & 26-Hydroxyporicoic acid DM & (Akihisa et al., 2009) \\
\hline 83 & Surface layer & 25-Hydroxyporicoic acid C & (Akihisa et al., 2009) \\
\hline 84 & Surface layer & Poricoic acid ZG & (Wang et al., 2018b) \\
\hline \multicolumn{4}{|c|}{ Other type triterpenes } \\
\hline 85 & Surface layer & $5 \alpha, 8 \alpha$-Peroxydehydrotumulosic acid & (Akihisa et al., 2007) \\
\hline 86 & Surface layer & 6,7-Dehydroporicoic acid H & (Akihisa et al., 2009) \\
\hline 87 & Surface layer & Daedaleanic acid D & (Chen B. et al., 2019) \\
\hline 88 & Surface layer & Daedaleanic acid E & (Chen B. et al., 2019) \\
\hline 89 & Surface layer & Daedaleanic acid F & (Chen B. et al., 2019) \\
\hline 90 & Surface layer & Daedaleanic acid A & (Chen B. et al., 2019) \\
\hline 91 & Surface layer & Poricoic acid ZH & (Wang et al., 2018b) \\
\hline
\end{tabular}

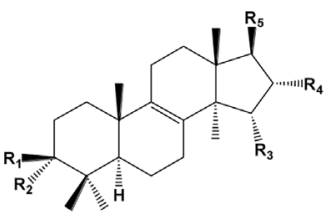

$1 \mathrm{R}_{\mathrm{l}}=\mathrm{OAc}, \mathrm{R}_{2}=\mathrm{H}, \mathrm{R}_{3}=\mathrm{H}, \mathrm{R}_{4}=\mathrm{OH}, \mathrm{R}_{5}=\mathrm{a}$ $2 \mathrm{R}_{1}=\mathrm{OH}, \mathrm{R}_{2}=\mathrm{H}, \mathrm{R}_{3}=\mathrm{H}, \mathrm{R}_{4}=\mathrm{OH}, \mathrm{R}_{5}=\mathrm{a}$ $3 \mathrm{R}_{1}=\mathrm{OH}, \mathrm{R}_{2}=\mathrm{H}, \mathrm{R}_{3}=\mathrm{H}, \mathrm{R}_{4}=\mathrm{H}, \mathrm{R}_{5}=\mathrm{a}$ $4 \mathrm{R}_{1}=\mathrm{OAc}, \mathrm{R}_{2}=\mathrm{H}, \mathrm{R}_{3}=\mathrm{H}, \mathrm{R}_{4}=\mathrm{OH}, \mathrm{R}_{5}=\mathrm{b}$ $5 \mathrm{R}_{1}=\mathrm{OH}, \mathrm{R}_{2}=\mathrm{H}, \mathrm{R}_{3}=\mathrm{H}, \mathrm{R}_{4}=\mathrm{OH}, \mathrm{R}_{5}=\mathrm{b}$ $6 \mathrm{R}_{1}=\mathrm{OH}, \mathrm{R}_{2}=\mathrm{H}, \mathrm{R}_{3}=\mathrm{H}, \mathrm{R}_{4}=\mathrm{H}, \mathrm{R}_{5}=\mathrm{b}$ $7 \mathrm{R}_{1}=\mathrm{OAc}, \mathrm{R}_{2}=\mathrm{H}, \mathrm{R}_{3}=\mathrm{H}, \mathrm{R}_{4}=\mathrm{OH}, \mathrm{R}_{5}=\mathrm{c}$

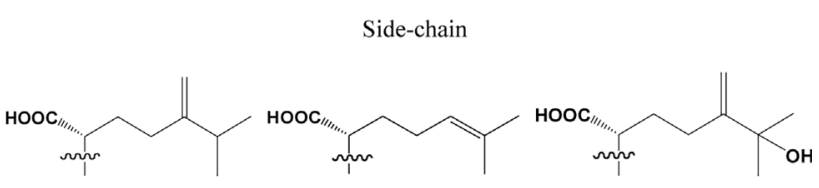

a

b

$8 \mathrm{R}_{1}=\mathrm{H}, \mathrm{R}_{2}=\mathrm{OH}, \mathrm{R}_{3}=\mathrm{H}, \mathrm{R}_{4}=\mathrm{OH}, \mathrm{R}_{5}=\mathrm{c}$

$9 \mathrm{R}_{1}, \mathrm{R}_{2}=\mathrm{O}, \mathrm{R}_{3}=\mathrm{H}, \mathrm{R}_{4}=\mathrm{OH}, \mathrm{R}_{5}=\mathrm{a}$

$10 \mathrm{R}_{1}, \mathrm{R}_{2}=\mathrm{O}, \mathrm{R}_{3}=\mathrm{H}, \mathrm{R}_{4}=\mathrm{OH}, \mathrm{R}_{5}=\mathrm{c}$

$11 \mathrm{R}_{1}=\mathrm{OAc}, \mathrm{R}_{2}=\mathrm{H}, \mathrm{R}_{3}=\mathrm{H}, \mathrm{R}_{4}=\mathrm{H}, \mathrm{R}_{5}=\mathrm{a}$

$12 \mathrm{R}_{1}=\mathrm{OAc}, \mathrm{R}_{2}=\mathrm{H}, \mathrm{R}_{3}=\mathrm{OAc}, \mathrm{R}_{4}=\mathrm{H}, \mathrm{R}_{5}=\mathrm{b}$

$13 \mathrm{R}_{1}, \mathrm{R}_{2}=\mathrm{O}, \mathrm{R}_{3}=\mathrm{H}, \mathrm{R}_{4}=\mathrm{H}, \mathrm{R}_{5}=\mathrm{b}$

$14 \mathrm{R}_{1}, \mathrm{R}_{2}=\mathrm{O}, \mathrm{R}_{3}=\mathrm{H}, \mathrm{R}_{4}=\mathrm{OH}, \mathrm{R}_{5}=\mathrm{b}$

FIGURE 2 | Structures of the lanosta-8-ene type triterpenes from Poria cocos.

The experiment results showed that S1-S6 time-dependently induced the apoptosis of HepG2 cell and facilitated the apoptosis of S-180 cells through regulating the expression of Bax and Bcl-2. It seemed that the sulfated derivative possessed the promise of drug exploitation as a chemotherapeutic drug
(Huang et al., 2006; Liu et al., 2019). CMP is transformed into WSP by enzymic hydrolysis. WSP can be further separated to obtain WSP-1 and WSP-2. WSP-1, WSP-2, and WSP all exhibited strong anti-proliferation activity against S180 both in vivo as well as in vitro. Their inhibition rates in vitro were found 


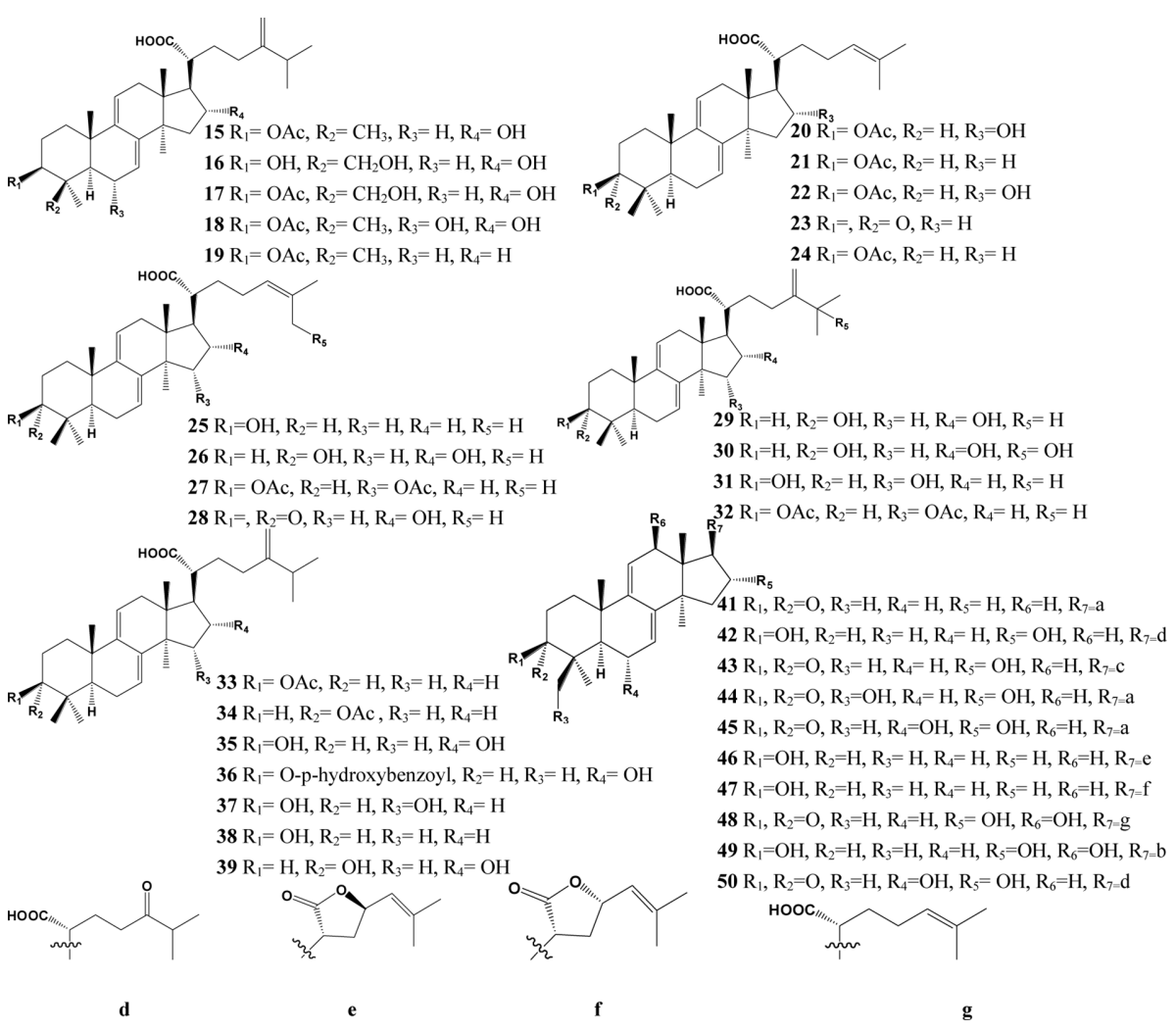

FIGURE 3 | Structures of the Lanosta-7,9(11)-diene type triterpenes from Poria cocos.
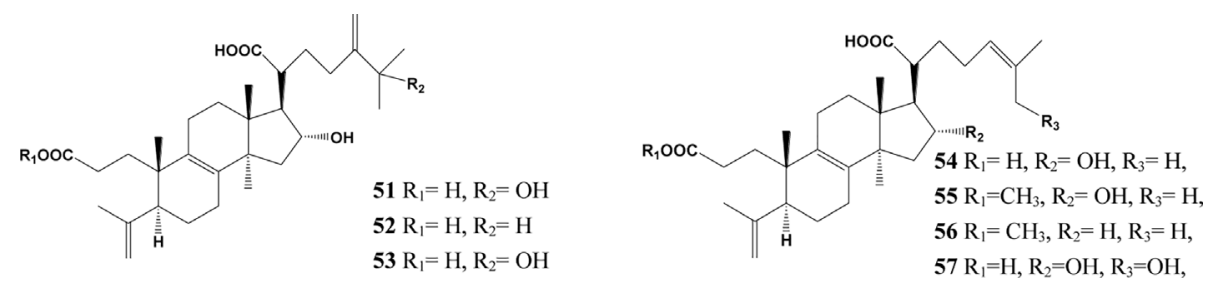

FIGURE 4 | Structures of the 3,4-seco-lanostan-8-ene type triterpenes from Poria cocos.

to be 2.2 to $4.0 \%$, higher than that of CMP. At the dose of 200 $\mathrm{mg} \cdot \mathrm{kg}^{-1}$, the inhibition rates of WSP, WSP-1 and WSP-2 in vivo were 43.94, 41.57, and 39.81\%, respectively (Bian et al., 2010). CMP33, A carboxymethyl polysaccharide with triple-helix structure isolated from Poria cocos, exhibited a strong and dose-dependent inhibition efficiency on four cancer cells (MCF-7, A549, HepG-2 and SGC-7901) (Liu et al., 2019). After PCP sulfated, methylated, carboxymethylated, hydroxyethylated, and hydroxypropylated respectively, their anticancer activity were determined. The sulfated and carboxymethylated products had obvious anti-tumor effects on S-180, MKN-45 and SGC-7901 cells. Therefore, it might be concluded that good water solubility, relatively high chain stiffness and moderate molecular mass of the derivatives in aqueous solution seemed to increase the anti-tumor activity of polysaccharides (Wang et al., 2004b).

It was reported that compound 1 obviously inhibited cell multiplication and induced apoptosis of DU145 prostate cancer cells dose-dependently and time-dependently. Meanwhile, Compound 1 reduced bad phosphorylation, promoted the phosphorylation of $\mathrm{Bcl}-2$ and activated caspases-3 and -9, indicating that it promoted apoptosis through inducing mitochondria dysfunction. Compound 1 also down-regulated the expression of proteins and decreased the activation of AKT 


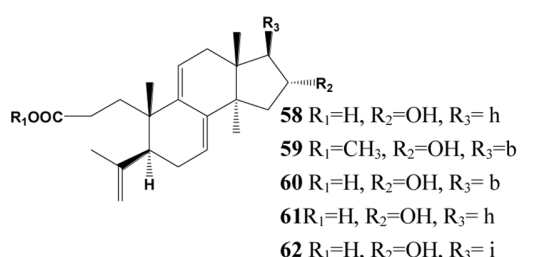

$62 \mathrm{R}_{1}=\mathrm{H}, \mathrm{R}_{2}=\mathrm{OH}, \mathrm{R}_{3}=\mathrm{i}$ $63 \mathrm{R}_{1}=\mathrm{CH}_{3}, \mathrm{R}_{2}=\mathrm{OH}, \mathrm{R}_{3}=\mathrm{i}$ $64 \mathrm{R}_{1}=\mathrm{CH}_{3}, \mathrm{R}_{2}=\mathrm{H}, \mathrm{R}_{3}=\mathrm{b}$

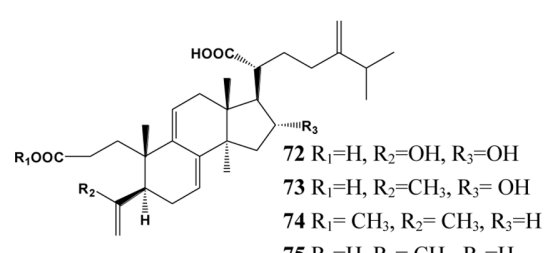
$75 \mathrm{R}=\mathrm{H}_{2} \mathrm{R}_{2}=\mathrm{CH}_{3}, \mathrm{R}_{3}=$ $76 \mathrm{R}_{1}=\mathrm{CH}_{3}, \mathrm{R}_{2}=\mathrm{CH}_{3}, \mathrm{R}_{3}=\mathrm{OH}$ $77 \mathrm{R}_{1}=\mathrm{CH}_{3} \mathrm{CH}_{2}, \mathrm{R}_{2}=\mathrm{CH}_{3}, \mathrm{R}_{3}=\mathrm{OH}$ $78 \mathrm{R}_{1}=\mathrm{CH}_{3} \mathrm{CH}_{2}, \mathrm{R}_{2}=\mathrm{CH}_{3}, \mathrm{R}_{3}=\mathrm{H}$

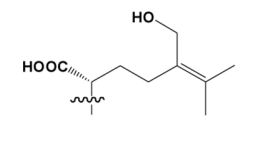

h

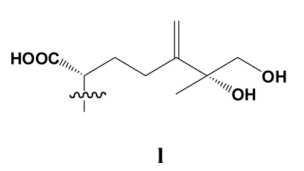<smiles>C/C(CO)=C(\CO)CCC(C(=O)O)C(=O)O</smiles>

i

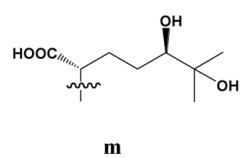

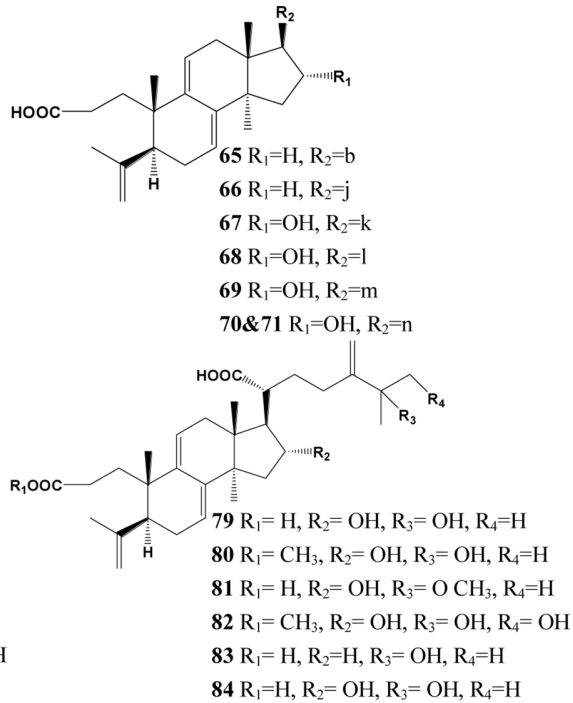

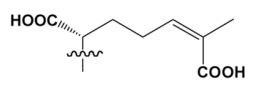

j

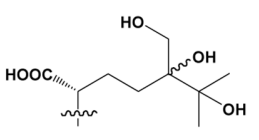

n

FIGURE 5 | Structures of the 3,4-seco-lanostan-7,9(11)-diene type triterpenes from Poria cocos.

signal pathway (Gapter et al., 2005). Compound 1 and 40 inhibited the inhibition activity against the expression of CDC20 which played an important role in cancer metastasis of PANC-1 cells dose-dependently by inhibiting the migration of pancreatic cancer cells (Cheng et al., 2019). Both compound 33 and 38 had a cytotoxicity effect on Molt 4 and HL 60 leukemic cell lines and targeting other than topoisomerases may be involved in the anti-proliferative activity (Lai et al., 2016). Compound 1 was discovered as a competing activator of PKM2, leading to a decreasing glucose uptake and lactate production in SK-BR-3 breast carcinoma cells, indicating that glycolysis was blocked or down-regulated to induce tumor cell proliferation (Miao et al., 2019). The results showed that compound $\mathbf{1}$ had markedly inhibition efficiency on human primary osteosarcoma cells proliferation concentration- and time-dependently. Meanwhile, compound 1 induced cell apoptosis dose-dependently, activated caspase 3, up-regulated PTEN expression and reduced AKT phosphorylation, demonstrating that compound 1 might be effective in treating human osteosarcoma (Wen et al., 2018). The anti-tumor activity of compound 1 was observed on nasopharyngeal carcinoma (NPC) cells and it was found that compound 1 might obviously inhibit cell proliferation and dose-dependently promote the apoptosis of the human NPC cells. Meanwhile, compound 1 caused morphological changes of the nucleus and up-regulated the expression of DNA damage-related proteins (Zhang et al., 2017). In addition, compound 1 could inhibit G0 phase arrest in gastric cancer cell lines SGC-7901 and MKN-49P. Moreover, Compound 1 regulated the expression of apoptosisrelated proteins (caspase-3, PARP, Bcl-2, and Bax), suppressed the mitochondrial capacity of gastric cancer cells dosedependently and finally induced cell apoptosis in vitro. Furthermore, compound 1 inhibited the tumor growth of xenograft models of gastric cancer and promoted the survival of animals obviously (Lu et al., 2017; Sun and Xia, 2018). In addition, compound 1 might inhibit tumorigenesis of gastric cancer cells through up-regulating the expression of Bax by suppressing hypoxia/HIF1 $\alpha$ (Lu et al., 2018). Triterpene acids extracted from the epidermis of Poria cocos were observed to inhibit the growth of lung cancer cells A549 in vitro and in vivo and the IC50 value of compound 1, the most abundant chemical ingredients of the extract, was found to be $34.6 \mu \mathrm{g} \cdot \mathrm{ml}^{-1}$, suggesting that compound 1 was the main anti-lung cancer ingredient in the triterpene acids (Dong et al., 2015). It was reported that compound 1 markedly inhibited the growth of gallbladder carcinoma cells dose- and time-dependently by inducing cell cycle arrest at G0 phase. Compound 1 also markedly reduced the migration and invasion of gallbladder 


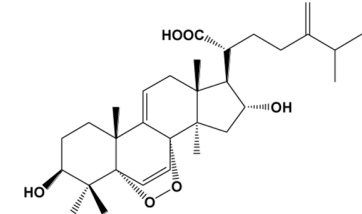

85

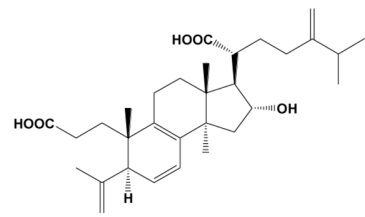

86<smiles>C=C(CC[C@H](C)C(=O)O)[C@H]1[C@@H](O)C[C@@]2(C)c3ccc(C)c(CCC(=O)C(C)C)c3C=C[C@]12C</smiles>

87

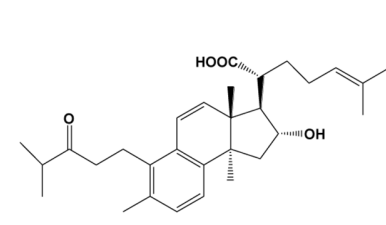

88

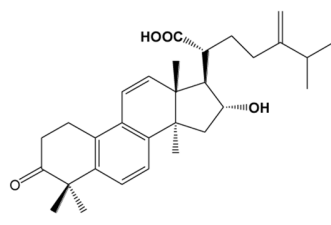

89<smiles>[SiH2][SiH2]</smiles>

90

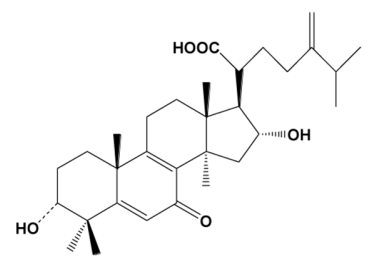

FIGURE 6 | Structures of other type triterpenes from Poria cocos.

carcinoma cells dose-dependently by suppressing cancer cell adhesion ability. Finally, it was demonstrated that compound 1 can inhibit gallbladder cancer tumorigenesis by affecting AKT and ERK signaling pathways (Chen et al., 2015).

\section{Anti-Oxidant Effects}

Reactive oxygen species produced by normal metabolism, such as hydroxyl radicals $(\cdot \mathrm{OH})$, superoxide anions $\left(\cdot \mathrm{O}^{2-}\right)$, and hydrogen peroxides ( $\mathrm{H} 2 \mathrm{O} 2$ ) could induce the peroxidation of membrane lipids, thus causing various illnesses including cancer, aging and angiocardiopathy (Zhang et al., 2013).

PCPs were extracted from Poria cocos by hot water extraction (PCP-H), ultrasonic-assisted extraction (PCP-U), enzymeassisted extraction (PCP-E), and microwave-assisted extraction (PCP-M), respectively. In vitro their antioxidant properties were determined on the basis of DPPH radical, reducing, power hydroxyl radical and metal chelating ability. PCP-M exhibited the highest reducing ability and strongest scavenging activity of hydroxyl radicals and DPPH radicals, while PCP-U showed the weakest antioxidant capacity (Wang et al., 2016). The water extracts from Poria cocos had protective effects on apoptosis in rat pheochro-mocytoma (PC12) cells apoptosis induced by Abeta1-42. The possible mechanisms were related to reducing the expression of Bax and the activity of caspase-3, indicating that Poria cocos had the potential to protect PC12 cells from apoptosis induced by oxidative stress (YH et al., 2009). Moreover, the water extracts showed the inhibition efficiency on lipid peroxidation induced by $\mathrm{FeCl} 2$-ascorbic acid in rat liver concentration-dependently. Its superoxide anion scavenging potency varied from 30.0 to $75.6 \%$, and its anti-superoxide potency ranged from 38.5 to $81.4 \%$ with the concentrations from 0.1 to $10.0 \mathrm{mg} \cdot \mathrm{ml}^{-1}$. It might be concluded that Poria cocos aqueous extracts exhibited a concentration-dependent anti-oxidant activity (Wu et al., 2004).

Compared with a native $\beta$-(1-3)-D-glucan obtained from Poria cocos, its carboxymethylated product had great improvement in solubility, ability to bind bile acids in vitro, and antioxidant activity. It can be hypothesized that the carboxymethylated derivative would have a beneficial effect on the decrease of cholesterol and blood pressure (Wang et al., 2009). Some researchers prepared the water-soluble oxidized product of (1-3)- $\beta$-D-glucan using TEMPO/NaBr $/ \mathrm{NaClO}$ oxidation system with Poria cocos as raw material. The oxidation enhanced the bile acid binding in vitro by improving water solubility and structural changes of polysaccharides. In addition, the derivative also had hydroxyl radical scavenging activity in vitro (Wang et al., 2011). The antioxidant activities of polysaccharides PCP-1, PCP-2, and PCP-3 from the degradation of PCPs with different concentrations of $\mathrm{H} 2 \mathrm{O} 2$ solution were studied by establishing in vitro systems, including scavenging effects on hydroxyl radicals, ABTS radicals and ferrous ions. The anti-oxidant properties of polysaccharides were concentration-dependent (Tang et al., 2014).

\section{Anti-Inflammatory Effects}

It is well known that inflammatory reaction is a common pathological phenomenon and widely exists in a variety of 
TABLE 2 | Summary of PCP from Poria cocos.

\begin{tabular}{|c|c|c|c|}
\hline $\begin{array}{l}\text { Compound } \\
\text { name }\end{array}$ & Monosaccharide composition & Structural features & References \\
\hline PCP & Manufactured by Hunan Butian Pharmaceutical Co, Ltd & ND & (Wu et al., 2019) \\
\hline PCP & Manufactured by Hunan Butian Pharmaceutical Co, Ltd & ND & (Wu et al., 2018) \\
\hline C-PCSG & ND & $\begin{array}{l}\text { Carboxymethylated } \\
(1,3)-\beta-\text { - } \text {-glucan }\end{array}$ & $\begin{array}{l}\text { (Wang and Zhang, 2006; Wang et al., } \\
\text { 2019a) }\end{array}$ \\
\hline CMP33 & ND & $\begin{array}{l}(1,3) \text { - } \alpha \text {-D-glucan } \\
\text { with some }(1,6) \text { - } \alpha \text { and }(1,2) \text { - } \alpha \text { branches }\end{array}$ & (Liu et al., 2018) \\
\hline PCP-1 & Ara : Glu=0.02:1 & $\mathrm{Mw}=2.33 \mathrm{kDa}$ & (Tang et al., 2014) \\
\hline PCP-2 & Ara : Glu=0.01:1 & $\mathrm{Mw}=3.20 \mathrm{kDa}$ & (Tang et al., 2014) \\
\hline PCP-3 & Ara : Glu=0.03:1 & $\mathrm{Mw}=2.85 \mathrm{kDa}$ & (Tang et al., 2014) \\
\hline CMP & Manufactured by Hunan Butian Pharmaceutical Co, Ltd & $\begin{array}{l}\text { Carboxymethylated } \\
(1,3)-\beta \text {-D-glucan with }(1,2)-\alpha \text { branches }\end{array}$ & (Wang et al., 2018a; Wang et al., 2019a) \\
\hline CMP33 & ND & $\mathrm{Mw}=15.23 \times 10^{4} \mathrm{Da}$ & (Liu et al., 2019) \\
\hline PCP & $\begin{array}{l}\text { Rib : Ara:Xyl : Man:Glu : Gal= } \\
\text { 1.49:1.17:0.62:10.34:86.39:1.31 }\end{array}$ & $\mathrm{Mw}=160 \mathrm{kDa}$ & (Pu et al., 2019) \\
\hline PCP & $\begin{array}{l}\text { Rib : Ara:Xyl : Man:Glu : Gal= } \\
\text { 1.49:1.17:0.62:10.34:86.39:1.31 }\end{array}$ & $\mathrm{Mw}=160 \mathrm{kDa}$ & (Tian et al., 2019) \\
\hline PCWPS & $\begin{array}{l}\text { Man : Glucose:Gal : Fuc= } \\
\text { 30.073:16.599:41.470:10.103 }\end{array}$ & $\mathrm{Mw}=186209 \mathrm{Da}$ & (Zhang et al., 2018) \\
\hline PCWPW & Man : Glucose:Gal : Fuc= 36.896:7.298:40.480:15.326 & $\mathrm{Mw}=37154 \mathrm{Da}$ & (Zhang et al., 2018) \\
\hline PCP-II & Fuc : Man:Glu : Gal= 1.00:1.63:0.16:6.29 & $\mathrm{Mw}=29.0 \mathrm{kDa}$ & (Lu et al., 2010; Wu L. et al., 2016) \\
\hline S-P & ND & $\begin{array}{l}\text { Sulfated }(1,3)-\alpha \\
\text {-D-glucan }\end{array}$ & (Wang W. et al., 2015) \\
\hline CMP & ND & Carboxymethyl $(1,3)-\alpha$-D-glucan & (Wang W. et al., 2015) \\
\hline S-CMP & ND & $\begin{array}{l}\text { Carboxymethylated-sulfated }(1,3)-\alpha-D \text { - } \\
\text { glucan }\end{array}$ & (Wang W. et al., 2015) \\
\hline PCP-II & Fuc : Man:Glu : Gal= 1.00:1.63:0.16:6.29 & $\mathrm{Mw}=29.0 \mathrm{kDa}$ & (Zhang G. et al., 2019) \\
\hline PCP-\| & Fuc : Man:Glu : Gal= 1.00:1.63:0.16:6.29 & $\mathrm{Mw}=29.0 \mathrm{kDa}$ & (Wu Y. et al., 2016) \\
\hline CMP1 & $\mathrm{ND}$ & $\mathrm{Mw}=25.27 \mathrm{kDa}$ & (Wang et al., 2012b) \\
\hline CMP2 & ND & $\mathrm{Mw}=25.75 \mathrm{kDa}$ & (Wang et al., 2012b) \\
\hline CMP3 & ND & $\mathrm{Mw}=27.88 \mathrm{kDa}$ & (Wang et al., 2012b) \\
\hline CMP4 & ND & $\mathrm{Mw}=30.92 \mathrm{kDa}$ & (Wang et al., 2012b) \\
\hline CMP5 & ND & $\mathrm{Mw}=36.00 \mathrm{kDa}$ & (Wang et al., 2012b) \\
\hline PCP & $\begin{array}{l}\text { Ara : Xyl:Man : Glc:Gal= } \\
\text { 1.09:0.54:11.3:85.9:1.01 }\end{array}$ & $\begin{array}{l}(1,3)-b-G l c,(1,4)- \\
\text { b-Man }\end{array}$ & (Ke et al., 2010) \\
\hline $\mathrm{H} 11$ & ND & $(1,3)-(1,6)-\beta$-D-glucan & (Kanayama et al., 1983) \\
\hline PCP & $\begin{array}{l}\text { Ara : Rib:Xyl : Man:Gal : Glu= } \\
\text { 1.17: 1.49:0.62:10.34:1.31:86.39 }\end{array}$ & ND & (Ke et al., 2010) \\
\hline PCSC & Man : Gal:Ara=92:6.2:1.3 & $\mathrm{Mw}=8.0 \mathrm{kDa}$ & (Lee et al., 2004) \\
\hline Pi-PCMO & $\begin{array}{l}\text { Ara : Xyl:Man : Gal:Glc= } \\
2.5: 1.5: 70.6: 18.5: 7.0\end{array}$ & $\mathrm{Mw}=6.46 \mathrm{kDa}$ & (Huang et al., 2007) \\
\hline Pi-PCM1 & $\begin{array}{l}\text { Fuc : Ara:Xyl : Man:Gal : Glc= } \\
\text { 10.9:1.0:2.8:23.6:36.5:25.2 }\end{array}$ & $\mathrm{Mw}=30.4 \mathrm{kDa}$ & (Huang et al., 2007) \\
\hline Pi-PCM2 & Man : Gal:Glc=29.6:38.9:29.7 & $\mathrm{Mw}=103 \mathrm{kDa}$ & (Huang et al., 2007) \\
\hline PCM3-II & ND & $(1,3)$ and $(1,4)-\beta$-D-glucan & (Zhang et al., 2006) \\
\hline acPCM2 & Fuc : Man:Gal : Glc=0.8:19.1:29.7:51.4 & $\mathrm{Mw}=17.0 \mathrm{kDa}$ & (Jin et al., 2003b) \\
\hline wcPCM2 & Fuc : Man:Gal : Glc=3.4:12.5:13.4:70.7 & $\mathrm{Mw}=89.2 \mathrm{kDa}$ & (Jin et al., 2003b) \\
\hline CS-PCS3-II & carboxymethylated-sulfated derivative & $(1 \rightarrow 3)$ - $\beta$-D-glucan & (Chen et al., 2010) \\
\hline ab-PCM3-I-S1 & ND & $\mathrm{Mw}=3.9 \mathrm{kDa}$ & (Lin et al., 2004) \\
\hline ab-PCM3-I-S2 & ND & $\mathrm{Mw}=11.3 \mathrm{kDa}$ & (Lin et al., 2004) \\
\hline ab-PCM3-I-S3 & ND & $\mathrm{Mw}=6.8 \mathrm{kDa}$ & (Lin et al., 2004) \\
\hline ab-PCM3-I-S4 & ND & $\mathrm{Mw}=5.8 \mathrm{kDa}$ & (Lin et al., 2004) \\
\hline ab-PCM3-I-S5 & ND & $\mathrm{Mw}=2.0 \mathrm{kDa}$ & (Lin et al., 2004) \\
\hline ac-PCM3-I-S1 & ND & $\mathrm{Mw}=17.4 \mathrm{kDa}$ & (Lin et al., 2004) \\
\hline ac-PCM3-I-S2 & ND & $\mathrm{Mw}=40.0 \mathrm{kDa}$ & (Lin et al., 2004) \\
\hline ac-PCM3-I-S3 & ND & $\mathrm{Mw}=26.1 \mathrm{kDa}$ & (Lin et al., 2004) \\
\hline ac-PCM3-I-S4 & ND & $\mathrm{Mw}=11.7 \mathrm{kDa}$ & (Lin et al., 2004) \\
\hline ac-PCM3-I-S5 & ND & $\mathrm{Mw}=4.7 \mathrm{kDa}$ & (Lin et al., 2004) \\
\hline S1 & Sulfated $(1,3)-\alpha$-D-glucan & $\mathrm{Mw}=14.5 \times 10^{4} \mathrm{Da}$ & (Huang et al., 2006) \\
\hline S2 & Sulfated $(1,3)-\alpha$-D-glucan & $\mathrm{Mw}=9.10 \times 10^{4} \mathrm{Da}$ & (Huang et al., 2006) \\
\hline S3 & Sulfated $(1,3)-\alpha$-D-glucan & $\mathrm{Mw}=6.88 \times 10^{4} \mathrm{Da}$ & (Huang et al., 2006) \\
\hline S4 & Sulfated $(1,3)-\alpha$-D-glucan & $\mathrm{Mw}=4.71 \times 10^{4} \mathrm{Da}$ & (Huang et al., 2006) \\
\hline S5 & Sulfated $(1,3)-\alpha$-D-glucan & $\mathrm{Mw}=3.50 \times 10^{4} \mathrm{Da}$ & (Huang et al., 2006) \\
\hline
\end{tabular}


TABLE 2 | Continued

\begin{tabular}{|c|c|c|c|}
\hline $\begin{array}{l}\text { Compound } \\
\text { name }\end{array}$ & Monosaccharide composition & Structural features & References \\
\hline S6 & Sulfated $(1,3)-\alpha$-D-glucan & $\mathrm{Mw}=2.65 \times 10^{4} \mathrm{Da}$ & (Huang et al., 2006) \\
\hline WSP & ND & $\mathrm{Mw}=1.75 \times 10^{5} \mathrm{Da}$ & (Bian et al., 2010) \\
\hline WSP-1 & ND & $\mathrm{Mw}=1.86 \times 10^{6} \mathrm{Da}$ & (Bian et al., 2010) \\
\hline WSP-2 & ND & $\mathrm{Mw}=3.58 \times 10^{4} \mathrm{Da}$ & (Bian et al., 2010) \\
\hline $\mathrm{PCP}-\mathrm{H}$ & Man : Gal:Glu: Ara= 0.92:0.18:86.88:12.01 & ND & (Wang et al., 2016) \\
\hline PCP-U & $\begin{array}{l}\text { Man : Gal:Glu : Ara }= \\
2.18: 2.36: 87.27: 8.18\end{array}$ & ND & (Wang et al., 2016) \\
\hline PCP-E & $\begin{array}{l}\text { Man : Gal:Glu : Ara }= \\
1.98: 0.36: 81.72: 15.93\end{array}$ & ND & (Wang et al., 2016) \\
\hline PCP-M & $\begin{array}{l}\text { Man : Gal:Glu : Ara }= \\
4.02: 4.93: 79.48: 11.57\end{array}$ & ND & (Wang et al., 2016) \\
\hline
\end{tabular}

Ara, araban; Xyl, xylose; Man, mannose; Glc, glucose; Gal, galactose; Fuc, fucose; Rha, rhamnose.

diseases. Not only cancers are strongly linked to inflammatory reaction, but their staging and prognosis are inversely associated with the expression of genes related to inflammation (Kim et al., 2012; Ma et al., 2013). It was found that PC-II, a polysaccharide from Poria cocos, inhibited the IFN- $\gamma$-induced production of inflammation marker IP-10 dose-dependently, demonstrating that PC-II might be a promising lead compound in the development of novel anti-inflammatory agents ( $\mathrm{Lu}$ et al., 2010). Notably, PC-II exhibited no toxicity to human vascular endothelial cells (ECs), indicating its safety. It was demonstrated that the expression of IP-10 was regulated by PC-II at the translational level rather than the transcriptional level, so it may participate in regulating inflammatory-related diseases ( $\mathrm{Lu}$ et al., 2010). Lee et al. revealed that treatment with PCP obviously promoted NO production and iNOS transcription in mouse RAW 264.7 cells by activating NF-kB/Rel, indicating that PCP could induce macrophages to produce NO by inducing the iNOS gene expression (Lee and Jeon, 2003). The effects of CMP33 from Poria cocos on inflammatory bowel disease (IBD) were studied with colitis induced by TNBS in mice. It was observed that CMP33 obviously ameliorated the colitis in mice by decreasing the levels of pro-inflammatory cytokines and increasing the levels of anti-inflammatory cytokines in the serum and colon tissue of colitic mice, demonstrating that CMP33 could protect IBD in mice through the potential TPG (targeting protein group) and PMP (key protein-metabolite pathways) (Liu et al., 2018).

Six triterpenoids were isolated from Poria cocos and their effects on the levels of NO and PGE2 (prostaglandin E2) and on the expression of inducible iNOS and COX-2 (cyclooxygenase-2) in LPS-induced Raw 264.7 cells were observed. The results showed that compound 1, 4, 6, 24, and 40 might inhibit the production of NO and expression of iNOS in LPS-induced Raw 264.7 cells. And compound 1 decreased PGE2 level by downregulating the expression of COX-2 (Lee et al., 2017). Compound 22 and 29 showed obvious inhibitory effects (IC50: 18.27 $\mu \mathrm{M}$ and $16.87 \mu \mathrm{M}$, respectively) on LPS-induced NO production by reducing the expression of inducible NO synthase enzymes in RAW 264.7 cells, which might be regulated via blocking the signaling pathway of activator protein-1 (Cai and Cai, 2011).

\section{Immunomodulation}

The immunomodulatory activities and the potential mechanisms of PCPs in RAW 264.7 macrophages were explored. It was observed that the levels of nitric NO, TNF- $\alpha$, IL- $1 \beta$, IL- 6 , and calcium were increased by PCPs in RAW 264.7 macrophages and the immunomodulatory effects of PCPs might be associated with the $\mathrm{Ca} 2+/ \mathrm{PKC} / \mathrm{p} 38 / \mathrm{NF}-\kappa \mathrm{B}$ signaling pathway ( $\mathrm{Pu}$ et al., 2019). The levels of NO, IL-2, IL-6, IL-17 A, TNF, and IFN- $\gamma$ were elevated in RAW 264.7 macrophages treated with PCPs and the expression of TLR4, MyD88, TRAF-6, p-NF- $\kappa B$, and p-c-JUN was significantly enhenced in mice, demonstrating that PCPs might show immunomodulatory activity via TLR4/TRAF6/NF$\kappa \mathrm{B}$ signaling pathway (Tian et al., 2019). It was observed that PCWPW and PCWPS inhibited T cell proliferation induced by ConA dose-dependently, and PCWPS protected the PC12 cells from damage induced by $\mathrm{H} 2 \mathrm{O} 2$ and inhibited $\mathrm{B}$ cell proliferation induced by LPS. These findings demonstrated that PCWPW and PCWPS have become promising immunosuppressive agents in food and pharmaceutical industries (Zhang et al., 2018). Furthermore, antigen-specific antibody levels in mice immunized with influenza vaccine were elevated by PCP-II, and the proliferation of splenocytes was improved. In addition, IL-12p70 and the production of TNF- $\alpha$ were induced by PCP-II. These results revealed that PCP-II-adjuvanted vaccines could strengthen humoral and cellular immunity (Wu et al., 2016). Poria cocos bark extract ameliorated the symptoms of food allergy (FA) and atopic dermatitis (AD) and increased the levels of Th2-related cytokines and the population of Foxp ${ }^{3+} \mathrm{CD}^{4+}$ Tregs in both $\mathrm{AD}$ and $\mathrm{FA}$, revealing that $\mathrm{PCB}$ extract could be a novel oral immunosuppressive agents for treating $\mathrm{AD}$ and FA through the production of Tregs (Bae et al., 2016). PCPs was sulfated (S-P), carboxymethyl (CMP), and carboxymethylated-sulfated (S-CMP), respectively. Of the three derivatives, the S-CMP owned the best immunological activity in vivo and the highest inhibition ratio against the implanted HepG2 tumor in BALB/c mice, with notable rise of hemolysin antibody titer in serum, the increase of the production of spleen antibody and the delay of type hypersensitivity (Wang $\mathrm{H}$. et al., 2015). 
TABLE 3 | Summary of pharmacological activities and mechanisms of Poria cocos.

\begin{tabular}{|c|c|c|c|c|c|}
\hline PharmacologicalEffects & Chemical component & Mechanism & Cell Lines/Model & $\begin{array}{c}\text { Dosage of } \\
\text { Administration }\end{array}$ & Ref. \\
\hline \multirow[t]{13}{*}{ Anticancer } & $\mathrm{H} 11$ & Inhibiting growth & $\begin{array}{l}\text { subcutaneous mouse } \\
\text { sarcoma S180 }\end{array}$ & 4 and $8 \mathrm{mg} \cdot \mathrm{kg}^{-1}$ & $\begin{array}{l}\text { (Kanayama et al., } \\
\text { 1986) }\end{array}$ \\
\hline & Pi-PCM0, Pi-PCM1 and Pi-PCM2 & inhibiting proliferation & $\begin{array}{l}\text { Sarcoma } 180 \\
\text { grown in mice }\end{array}$ & $20 \mathrm{mg} \cdot \mathrm{kg}^{-1}$ & (Huang et al., 2007) \\
\hline & PCM3-॥ & $\begin{array}{l}\text { Reducing proliferation and } \\
\text { viability and inducing cell-cycle } \\
\text { G1 arrest }\end{array}$ & $\begin{array}{l}\text { human breast carcinoma } \\
\text { MCF-7 cells }\end{array}$ & $400 \mu \mathrm{g} \cdot \mathrm{ml}^{-1}$ & (Zhang et al., 2006) \\
\hline & ac-PCM2 and wc-PCM2 & $\begin{array}{l}\text { inhibiting } \\
\text { growth }\end{array}$ & $\begin{array}{l}\text { Sarcoma } 180 \text { solid tumor } \\
\text { grown in BALB/c mice }\end{array}$ & $20 \mathrm{mg} \cdot \mathrm{kg}^{-1}$ & (Jin et al., 2003b) \\
\hline & CS-PCS3-॥ & $\begin{array}{l}\text { increasing necrosis and } \\
\text { apoptosis and immunological } \\
\text { responses in tumor cells }\end{array}$ & $\begin{array}{l}\text { Sarcoma } 180 \text { solid tumor } \\
\text { grown in BALB/c mice }\end{array}$ & $20 \mathrm{mg} \cdot \mathrm{kg}^{-1}$ & (Chen et al., 2010) \\
\hline & S1- S6 & $\begin{array}{l}\text { inducing and facilitating } \\
\text { apoptosis }\end{array}$ & $\begin{array}{l}\text { HepG2 and S-180 tumor } \\
\text { cells }\end{array}$ & $20 \mathrm{mg} \cdot \mathrm{kg}^{-1}$ & (Huang et al., 2006) \\
\hline & WSP, WSP-1 and WSP-2 & anti-proliferation & S180 tumor cells & $\begin{array}{l}100 \text { and } 200 \\
\mathrm{mg} \cdot \mathrm{kg}^{-1}\end{array}$ & (Bian et al., 2010) \\
\hline & CMP33 & inhibiting growth & $\begin{array}{l}\text { MCF-7, A549, HepG-2 } \\
\text { and SGC-7901 cells }\end{array}$ & $1 \mathrm{mg} \cdot \mathrm{ml}-1$ & (Liu et al., 2019) \\
\hline & $\begin{array}{l}\text { Dehydropachymic acid and } \\
\text { Dehydroeburicoic acid }\end{array}$ & anti-proliferative activity & Molt 4 and HL 60 cells & - & (Lai et al., 2016) \\
\hline & Pachymic acid & $\begin{array}{l}\text { inducing apoptosis by resulting in } \\
\text { mitochondria dysfunction }\end{array}$ & DU145 cells & $40 \mathrm{mg} \cdot \mathrm{kg}-1$ & (Zhang et al., 2005) \\
\hline & Pachymic acid & $\begin{array}{l}\text { inhibiting-proliferation by } \\
\text { activating caspase } 3 \text {, up- } \\
\text { regulating PTEN expression and } \\
\text { reducing AKT phosphorylation }\end{array}$ & $\begin{array}{l}\text { primary osteosarcoma } \\
\text { cells }\end{array}$ & $10-50 \mu \mathrm{g} \cdot \mathrm{ml}^{-1}$ & (Wen et al., 2018) \\
\hline & Pachymic acid & $\begin{array}{l}\text { Inhibiting proliferation and } \\
\text { inducing apoptosis by up- } \\
\text { regulating the expression of DNA } \\
\text { damage-related proteins }\end{array}$ & NPC cells & $10-30 \mu \mathrm{M}$ & (Zhang et al., 2017) \\
\hline & Pachymic acid & Decreased cell viability & $\begin{array}{l}\text { SGC-7901 and MKN- } \\
\text { 49P cells }\end{array}$ & $15-240 \mu \mathrm{mol} \cdot \mathrm{L}^{-1}$ & (Lu et al., 2017) \\
\hline \multirow[t]{2}{*}{ Anti-Oxidant } & $\begin{array}{l}\text { PCP-H, PCP-U, PCP-E and PCP- } \\
M\end{array}$ & $\begin{array}{l}\text { reducing and scavenging } \\
\text { hydroxyl and DPPH radicals }\end{array}$ & - & - & (Wang et al., 2016) \\
\hline & PCP-1, PCP-2 and PCP-3 & $\begin{array}{l}\text { scavenging hydroxyl radicals, } \\
\text { ABTS radicals and ferrous ions }\end{array}$ & - & - & \\
\hline \multirow[t]{3}{*}{ Anti-inflammatory } & PC-II & $\begin{array}{l}\text { inhibiting the production of IP-10 } \\
\text { induced by IFN- } \gamma\end{array}$ & & & (Lu et al., 2010) \\
\hline & CMP33 & $\begin{array}{l}\text { improving colitis by decreasing } \\
\text { levels of pro-inflammatory } \\
\text { cytokines and increasing levels of } \\
\text { anti-inflammatory cytokines }\end{array}$ & $\begin{array}{l}\text { mice with inflammatory } \\
\text { bowel disease (IBD) }\end{array}$ & & (Liu et al., 2018) \\
\hline & $\begin{array}{l}\text { Pachymic acid, Trametenolic acid } \\
\text { and Polyporenic acid C }\end{array}$ & $\begin{array}{l}\text { inhibiting NO production and } \\
\text { iNOS expression }\end{array}$ & RAW 264.7 cells & & (Lee et al., 2017) \\
\hline \multirow[t]{2}{*}{ Immunomodulation } & PCWPW and PCWPS & inhibited T cell proliferation & PC12 cells & & (Zhang et al., 2018) \\
\hline & S-P, CMP and S-CMP & $\begin{array}{l}\text { Increasing hemolysin antibody } \\
\text { titer and antibody }\end{array}$ & $\begin{array}{l}\text { implanted HepG2 tumor } \\
\text { in BALB/c mice }\end{array}$ & & $\begin{array}{l}\text { (Wang W. et al., } \\
\text { 2015) }\end{array}$ \\
\hline \multirow[t]{2}{*}{ Kidney protection } & Poricoic acid ZL, Zl and ZK & $\begin{array}{l}\text { down-regulating profibrotic } \\
\text { protein expression }\end{array}$ & $\begin{array}{l}\text { HK-2, NRK-52E and } \\
\text { NRK-49F cells }\end{array}$ & & $\begin{array}{l}\text { (Chen L. et al., } \\
\text { 2019) }\end{array}$ \\
\hline & Poricoic acid A & $\begin{array}{l}\text { decreasing the elevated levels of } \\
\text { creatinine and urea and } \\
\text { improving renal fibrosis and } \\
\text { podocyte injury }\end{array}$ & $\begin{array}{l}\text { rats and renal NRK-52E } \\
\text { cells }\end{array}$ & & $\begin{array}{l}\text { (Chen D. et al., } \\
\text { 2019) }\end{array}$ \\
\hline Liver protection & PCPs & $\begin{array}{l}\text { decreasing the levels of ALT, LD, } \\
\text { TNF- } \alpha \text { and IL- } 6\end{array}$ & $\begin{array}{l}\text { liver injury mice induced } \\
\text { by APAP }\end{array}$ & & (Wu et al., 2018) \\
\hline
\end{tabular}

Compound $1,2,16,17,33,35,40$, and 44 reduced the production of NO induced by LPS in RAW 264.7 cells dosedependently. Of these, Compound 40 and 44 exhibited the higher inhibitory activity (IC50: $16.8 \pm 2.7 \mu \mathrm{m}$ and $18.2 \pm$ $3.3 \mu \mathrm{m}$, respectively). In addition, the inhibited NO release might be related to the intervention of protein-1 signaling pathway (Cai and Cai, 2011).

The results suggested that immunomodulatory protein from Poria cocos might upregulate TNF- $\alpha$ and IL- $1 \beta$ transcription and promote TNF- $\alpha$ production in RAW 264.7 cells (Li H. et al., 2019). 


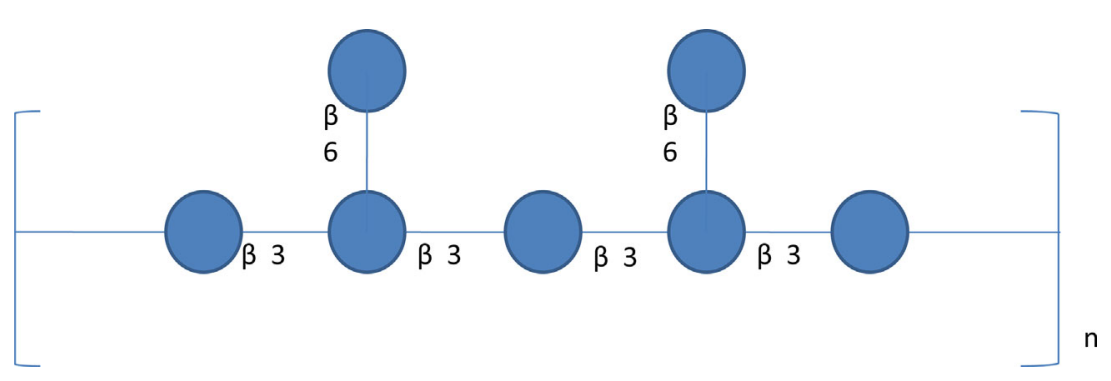

FIGURE 7 | A schematic diagram of $\beta$-glucan structure in Poria cocos. $\beta$-Glucan is the major Poria cocos polysaccharide with $\beta$-(1 $\rightarrow 3$ ) linked glucose backbone and $\beta$ - $(1 \rightarrow 6)$-linked glucose side chains. The $\beta$-glucan from Poria cocos has poor water solubility but decent anticancer activity.

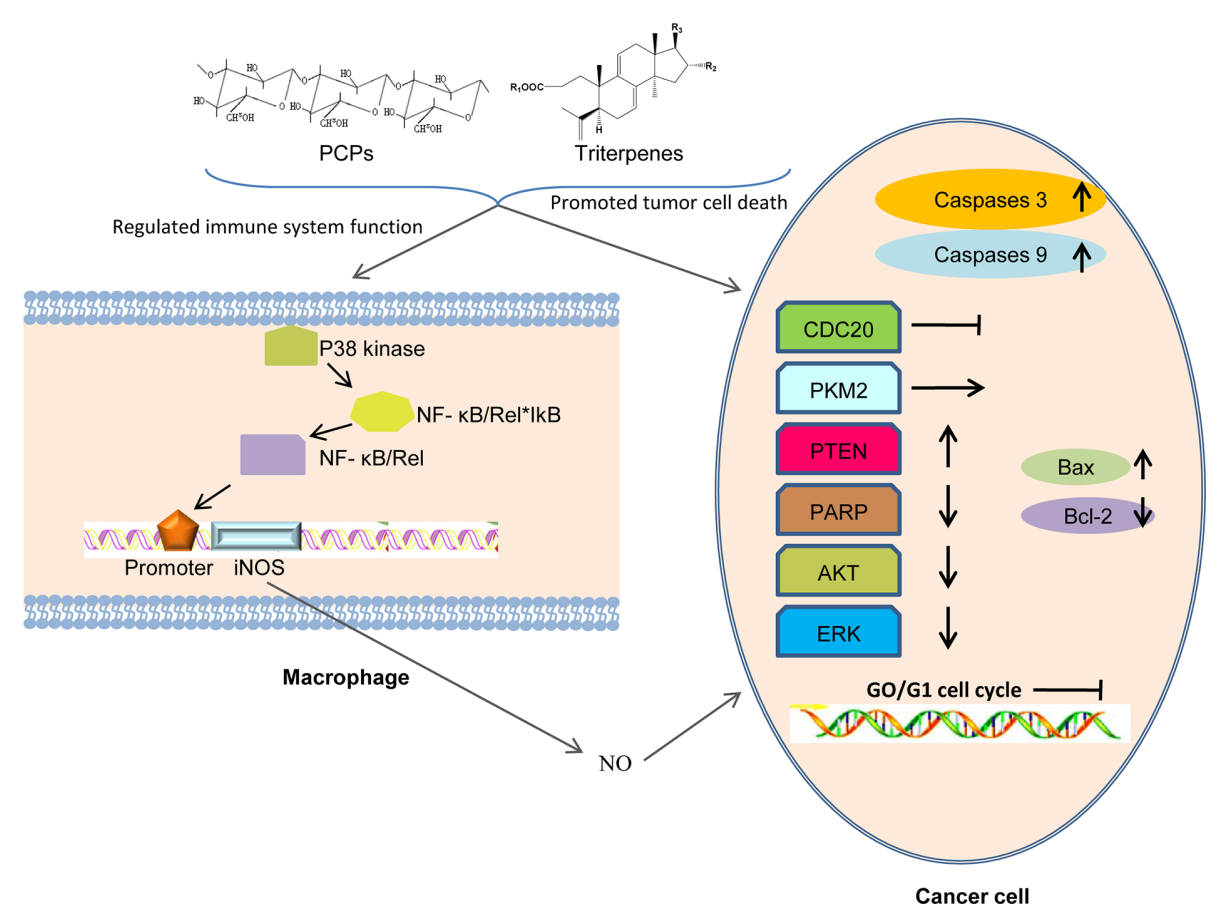

FIGURE 8 | Possible anti-tumor mechanisms of PCPs. PCPs and triterpenes exert their antitumor activity via assisting the host to overcome adverse biological stresses, to enhance the lethality of macrophages by releasing cytokines to increase immunity, and to promote the apoptosis of tumor cells directly by up-regulating the expression of apoptosis-related genes.

\section{Kidney Protection}

It was observed that compound 49,50 , and 56 inhibited the expression of profibrotic protein in NRK-49F, NRK-52E, and HK-2 cells, indicating that the three kinds of poricoic acids could inhibit epithelial-mesenchymal transition (EMT). Compound 50 showed stronger inhibition of protein expression and activation of MMP-13 than compound 49 and 56. Thence, Compound 50 had potential as a novel agent for treating EMT and renal fibrosis (Chen L. et al., 2019). It was observed that compound 73 could weakened AKI-to-CKD transition in rats and renal NRK-52E cells. Firstly, compound 73 obviously decreased the elevated levels of creatinine and urea and improved renal fibrosis and cellular damage in IRI rats by inhibiting oxidative stress via NF$\kappa \mathrm{B} / \mathrm{Nrf} 2$ pathways, indicating that compound 73 could block AKI-to-CKD transition through regulating growth arrestspecific 6 (Gas6)/Axl-NF $-\kappa B / N r f 2$ signaling cascade (Chen D. et al., 2019). Wang et al. revealed that compound 84 and 91 isolated from Poria cocos attenuated renal injury via the $\mathrm{Wnt} / \beta$ Catenin and TGF- $\beta /$ Smad pathway and selectively attenuated the phosphorylation of Smad3 by blocking the interaction between SARA, TGF $\beta$ I and Smad3 (Wang et al., 2018b). It was revealed that compound 57 had the capacity to inhibit RAS and further suppress TGF $\beta 1 / \mathrm{Smad}$ pathway through inhibiting Smad2/3 phosphorylation via blocking Smad2/3-TGFßRI 
protein interaction, and compound 57 was implicated in activation of RAS/TGF $\beta 1 / \mathrm{Smad}$ axis in HK-2 cells and podocytes, indicating that compound 57 played a beneficial role in renal fibrosis and podocyte injury and could be considered as a novel RAS inhibitor for treating CKD (Wang et al., 2017). The effect of Poria cocos hydroethanolic extract on nephrotic syndrome (NS) in rats were also evaluated. The results showed that the levels of urine protein and serum total protein (TP), albumin (Alb), globulin (Glo), total cholesterol (TC), and interlukin-4 (IL-4) were all improved in rats treated with PHE, indicating that PHE might be developed as a group of effective compounds for the treatment of NS (Zan et al., 2017). One previous study demonstrated that "Fu-Ling-Pi" treatment could improve CKD in major metabolic pathways including adenine metabolism and amino acid metabolism (Zhao et al., 2013).

\section{Hepatoprotective Effects}

$\mathrm{Wu}$ et al. investigated the effects of PCPs on acetaminophen (APAP)-induced liver injury in mice. In mice treated with PCPs, the dropped ALT, LD, TNF- $\alpha$ and IL- 6 serum level and the inhibited inflammatory infiltration and cell apoptosis in liver tissue were observed. The results indicated that PCPs had pharmacological activity against liver damage induced by APAP in mice, and the potential mechanisms were related to alleviating inflammatory reaction and apoptosis in liver cells (Wu et al., 2018). The reduced inflammatory cytokines (TNF- $\beta$ and TNFsR- $\beta$ ), enzymological molecules (AST, ALT, and LDL), and heat shock protein 90 (Hsp90) levels were observed after APAP exposure, elucidating that PCPs had hepatoprotective effects on liver cells with the potential mechanisms of inhibiting cell death, reducing hepatocellular inflammatory stress and Hsp90 bioactivity (Wu et al., 2019).

\section{Anti-Bacterial Effects}

The effects of CMP added with lotus seedpod oligomeric procyanidins (LSPC) on Escherichia coli 10899 were observed. When mixed with a small amount of LSPC, the antibacterial effect of CMP was synergistically enhanced, especially when the concentration of CMP was below its critical concentration (1.35 $\mathrm{mg} / \mathrm{ml}$ ) (Wang et al., 2019a). Antibacterial activity experiments demonstrated that the growth of the carboxymethylated derivative of PCPs significantly inhibited the growth of Pseudomonas aeruginosa (Wang et al., 2010).

\section{Others}

CMP ameliorated the enteric dysbacteriosis induced by 5 -FU through regulating the proportion of bacteroidetes, lactobacilli, and butyric acid-producing and acetic acid-producing bacteria as well as restoring the enteric flora diversity of CT26 tumorbearing mice, which might be related to the intervention of the NF- $\mathrm{KB}, \mathrm{Nrf2-ARE}$ and MAPK/P38 pathways (Wang C. et al., 2018). Research results showed that ethanol extract of cultured Poria cocos mycelia markedly increased urinary volume, $\mathrm{Na}^{+}$and $\mathrm{Cl}^{-}$excretion, and $\mathrm{Na}^{+} / \mathrm{K}^{+}$ratio, suggesting its obvious diuretic activity in rats (Hu et al., 2017). Experiments in vitro showed that 10,20 , and $40 \mu \mathrm{g} / \mathrm{ml}$ Trametenolic acid B protected SH-SY5Y cell against damage induced by $\mathrm{OGD} / \mathrm{R}$ through inducing cellular proliferation and inhibiting $\mathrm{LDH}$ leakage. The results in vivo exhibited that TAB $(20,40$, and $80 \mathrm{mg} / \mathrm{kg})$ might obviously improve the neurological impairment score, encephaledema, neuronal cell loss and apoptosis, and inhibit brain infarction volume of the cerebral I/R injury rats. It manifested that TAB possessed neuroprotective potency against ODG/R and $I / R$ damage by inhibiting miR-10a expression and activating PI3K/ Akt/mTOR signaling pathway to reduce mitochondrialmediated apoptosis, which provided a new insight for interpreting the underlying mechanisms of TAB' neuroprotective effects and a candidate agent to treat cerebral I/R injury (Wang et al., 2019b). It was observed that the EtOH extract of Poria cocos sclerotia was able to inhibit MSC differentiation toward adipocytes and promote osteogenic differentiation of MSC (Lee et al., 2018a). In addition, PCP improved osteoclastogenesis induced by RANKL throug inhibiting NFATc1 activity and phosphorylation of ERK and STAT3 (Song et al., 2018).

\section{Toxicological Evidence}

Poria cocos has low toxicity to mice and there was no problem with oral administration of 6-18 g per day (Cuellar et al., 1997). Xiao Banxia plus fuling decoction constituted of Poria cocos, Pinellia ternata, and Zingiber officinale, which was effective drug for vomiting. The mice were given Xiao Banxia plus fuling decoction at the maximum concentration $\left(0.4 \mathrm{ml} \cdot 10 \mathrm{~g}^{-1}\right.$ each mice for $2.23 \mathrm{~g} \cdot \mathrm{ml}^{-1}$, which was 382.29 times daily oral dose for adult in clinical) for three times within $24 \mathrm{~h}$ for 7 days. Then, the index of normal physiological state such as diet, stool and piss and death amount of the mice were observed and recorded. The results revealed that Xiao Banxia plus fuling decoction had no obvious toxic effect (Wang et al., 2013). Compound fuling and liquorice decoction contains Poria cocos, Cinnamomum cassia, Prunus persica, Fritillariae Cirrhosae, and Anemarrhena asphodeloides, which is usually used to treat chronic obstructive emphysema. Acute and long term toxicity test of compound fuling and liquorice decoction were executed. In the acute toxicity test, the rats were given compound fuling and liquorice decoction at the concentration of $720 \mathrm{~g} \cdot \mathrm{kg}^{-1}$, which was 100 times patient's daily administration dosage and all rats had no significant poisoning reaction. In long term toxicity test, there was no significant difference between the high-dose group (360 g. $\left.\mathrm{kg}^{-1}\right)$, the middledose group (180 g.kg-1) the low-dose group (90 g. $\left.\mathrm{kg}^{-1}\right)$ dose groups and the control group. Thus, we can draw conclusion that Poria cocos have no cumulative toxicity and is security for the clinical application (Wang et al., 2013).

\section{CONCLUSIONS}

Over the years, Poria cocos has attracted increasing interest, and relevant phytochemical and pharmacological researches have validated its traditional uses. A lot of pharmacological effects, including anti-tumor, anti-oxidant, anti-inflammatory, hepatoprotective, antibacterial, kidney protection, and immunomodulation are summarized 
in the review. Furthermore, Poria cocos is secure for clinical application without obvious toxicity.

Pharmacological and phytochemical researches of the crude extracts and chemical composition isolated from Poria cocos are getting more and more researcher's concerning recently. In 2006, PCPs-based product called "compound polysaccharide oral solution" was developed by Hunan Butian pharmaceutical company of China and was granted a Chinese patent (200610163425-X). The major ingredient in the patented product is CMP (95\%, w/w). In 2015, "Polysaccharidum of Poria cocos oral solution" was approved by Chinese Food and Drug Administration with a certified drug number B20050015 for treating many kinds of cancers, hepatitis, and other diseases alone or as adjuvant drug during chemo- or radiation therapy for cancer patients (Li X. et al., 2019). The relationship between the molecular mass, chain stiffness and water solubility of PCPs and the anti-tumor activity needs to be further studied and confirmed. Besides, clinical trials of Poria cocos are still lacking, which limits its therapeutic application.

Due to the low yield, difficult separation, and purification of natural active polysaccharide from Poria cocos, its reports on the biological activity are mainly limited to the crude extract or derivative, and the fine structure of polysaccharides is unclear. The comprehensive application of biomodification and chemical modification may be a new direction to further elucidate the

\section{REFERENCES}

Akihisa, T., Nakamura, Y., Tokuda, H., Uchiyama, E., Suzuki, T., Kimura, Y., et al. (2007). Triterpene acids from Poria cocos and their anti-tumor-promoting effects. J. Nat. Prod. 70 (6), 948-953. doi: 10.1021/np0780001

Akihisa, T., Uchiyama, E., Kikuchi, T., Tokuda, H., Suzuki, T., and Kimura, Y. (2009). Anti-tumor-promoting effects of 25-methoxyporicoic acid A and other triterpene acids from Poria cocos. J. Nat. Prod. 72 (10), 1786-1792. doi: 10.1021/np9003239

Bae, M., See, H., Choi, G., Kang, C., Shon, D., and Shin, H. (2016). Regulatory T Cell Induced by Poria cocos Bark Exert Therapeutic Effects in Murine Models of Atopic Dermatitis and Food Allergy. Mediators Inflamm. 2016, 3472608. doi: 10.1155/2016/3472608

Bian, C., Xie, N., and Chen, F. (2010). Preparation of bioactive water-soluble pachyman hydrolyzed from sclerotial polysaccharides of Poria cocos by hydrolase. Polymer. J. 42 (3), 256-260. doi: 10.1038/pj.2009.329

Cai, T., and Cai, Y. (2011). Triterpenes from the fungus Poria cocos and their inhibitory activity on nitric oxide production in mouse macrophages via blockade of activating protein-1 pathway. Chem. Biodivers 8 (11), 21352143. doi: $10.1002 / \mathrm{cbdv} .201100013$

Chen, X., Zhang, L., and Cheung, P. (2010). Immunopotentiation and anti-tumor activity of carboxymethylated-sulfated beta-(1->3)-d-glucan from Poria cocos. Int. Immunopharmacol. 10 (4), 398-405. doi: 10.1016/j.intimp. 2010.01.002

Chen, Y., Lian, P., Liu, Y., and Xu, K. (2015). Pachymic acid inhibits tumorigenesis in gallbladder carcinoma cells. Int. J. Clin. Exp. Med. 8 (10), 17781-17788.

Chen, B., Zhang, J., Han, J., Zhao, R., Bao, L., Huang, Y., et al. (2019). Lanostane Triterpenoids with Glucose-Uptake-Stimulatory Activity from Peels of the Cultivated Edible Mushroom Wolfiporia cocos. J. Agric. Food Chem. 67 (26), 7348-7364. doi: 10.1021/acs.jafc.9b02606

Chen, D., Feng, Y., Chen, L., Liu, J., Wang, M., Vaziri, N., et al. (2019). Poricoic acid A enhances melatonin inhibition of AKI-to-CKD transition by regulating Gas6/AxlNFאB/Nrf2 axis. Free Radical Biol. Med. 134, 484-497.

Chen, L., Cao, G., Wang, M., Feng, Y., Chen, D., Vaziri, N., et al. (2019). The Matrix Metalloproteinase-13 Inhibitor Poricoic Acid ZI Ameliorates Renal structure-activity relationship of PCPs and facilitate the development of new polysaccharide drugs or biomaterials.

In conclusion, PCPs and triterpenes are promising agents to treat various diseases or act as functional components in food products.

\section{AUTHOR CONTRIBUTIONS}

$\mathrm{AN}$ and YC searched the literature, collected the data, and drafted the manuscript. ZZ and CZ contributed to analysis and manuscript preparation. $\mathrm{XZ}$ and $\mathrm{WJ}$ helped in checking the chemical structures. AN and ZZ downloaded the documents and made classification. $\mathrm{CZ}$ and $\mathrm{AN}$ contributed comments for version of the manuscript. All authors contributed to the article and approved the submitted version.

\section{FUNDING}

This work was supported by the Chinese Medical Association Clinical Pharmaceutical Branch Youth Fund (LCYX-Q025). The authors would like to thank Enago (www.enago.cn) for the English language review.
Fibrosis by Mitigating Epithelial-Mesenchymal Transition. Mol. Nutr. Food Res. e1900132. doi: 10.1002/mnfr.201900132

Cheng, S., Victor, C., and Sliva, D. (2019). CDC20 associated with cancer metastasis and novel mushroom-derived CDC20 inhibitors with antimetastatic activity. Int. J. Oncol. 54 (6), 2250-2256. doi: 10.3892/ijo.2019.4791

Chihara, G., Hamuro, J., Maeda, Y., Arai, Y., and Fukuoka, F. (1970). Antitumor polysaccharide derived chemically from natural glucan (pachyman). Nature 225 (5236), 943-944. doi: 10.1038/225943a0

Cuellar, M., Giner, R., Recio, M., Just, M., Mañez, S., and Rios, J. (1997). Effect of the basidiomycete Poria cocos on experimental dermatitis and other inflammatory conditions. Chem. Pharm. Bull. 45 (3), 492-494. doi: 10.1248/cpb.45.492

Dong, H., Wu, P., Yan, R., Xu, Q., Li, H., Zhang, F., et al. (2015). Enrichment and separation of antitumor triterpene acids from the epidermis of Poria cocos by $\mathrm{pH}$-zone-refining counter-current chromatography and conventional highspeed counter-current chromatography. J. Sep Sci. 38 (11), 1977-1982. doi: 10.1002/jssc.201500077

Eom, S., Kim, Y., Lee, S., Noh, S., Yeom, H., Bae, H., et al. (2018a). Molecular Determinants of $\alpha 3 \beta 4$ Nicotinic Acetylcholine Receptors Inhibition by Triterpenoids. Biol. Pharm. Bull. 41 (1), 65-72. doi: 10.1248/bpb.b17-00576

Fu, M., Wang, L., Wang, X., Deng, B., Hu, X., and Zou, J. (2018). Determination of the Five Main Terpenoids in Different Tissues of Wolfiporia cocos 23, 8, 1839. doi: $10.3390 /$ molecules23081839

Gapter, L., Wang, Z., Glinski, J., and Ng, K. (2005). Induction of apoptosis in prostate cancer cells by pachymic acid from Poria cocos. Biochem. Biophys. Res. Commun. 332 (4), 1153-1161. doi: 10.1016/j.bbrc.2005.05.044

Hsu, H., Yang, J., Lian, S., Ho, Y., and Lin, C. (1996). Recovery of the hematopoietic system by Si-Jun-Zi-Tang in whole body irradiated mice. J. Ethnopharmacol. 54 (2-3), 69. doi: 10.1016/s0378-8741(96)01450-x

Hu, G., Huang, C., Zhang, Y., Xiao, W., and Jia, J. (2017). Accumulation of biomass and four triterpenoids in two-stage cultured Poria cocos mycelia and diuretic activity in rats. Chin. J. Natural Medicines 15 (4), 265-270. doi: 10.1016/S1875-5364(17)30043-2

Huang, Q., and Zhang, L. (2005). Solution properties of (1->3)-alpha-D-glucan and its sulfated derivative from Poria cocos mycelia via fermentation tank. Biopolymers 79 (1), 28-38. doi: 10.1002/bip.20332 
Huang, Q., Zhang, L., Cheung, P., and Tan, X. (2006). Evaluation of sulfated $\alpha$ glucans from Poria cocos mycelia as potential antitumor agent. Carbohydr. Polymer. 64 (2), 337-344. doi: 10.1016/j.carbpol.2005.12.001

Huang, Q., Jin, Y., Zhang, L., Cheung, P., and Kennedy, J. (2007). Structure, molecular size and antitumor activities of polysaccharides from Poria cocos mycelia produced in fermenter. Carbohydr. Polymer. 70 (3), 324-333. doi: 10.1016/j.carbpol.2007.04.015

Huang, H., Wang, S., Nguyen, V., and Kuo, Y. (2018). Isolation and Identification of Potent Antidiabetic Compounds from Antrodia cinnamomea-An Edible Taiwanese Mushroom. Molecules 23 (11):2864. doi: 10.3390/molecules23112864

Ji, B., Zhao, B., Yu, P., Yang, B., Zhou, C., and Yu, Z. (2018). LC-ESI-MS/MS method for simultaneous determination of eleven bioactive compounds in rat plasma after oral administration of Ling-Gui-Zhu-Gan Decoction and its application to a pharmacokinetics study. Talanta 190, 450-459. doi: 10.1016/ j.talanta.2018.08.020

Jia, X., Ma, L., Li, P., Chen, M., and He, C. (2016). Prospects of Poria cocos polysaccharides: Isolation process, structural features and bioactivities. Trends Food Sci. Technol. 54 (2016), 52-62. doi: 10.1016/j.tifs.2016.05.021

Jin, Y., Zhang, L., Chen, L., Chen, Y., Cheung, P., and Chen, L. (2003a). Effect of culture media on the chemical and physical characteristics of polysaccharides isolated from Poria cocos mycelia. Carbohydr. Res. 338 (14), 1507-1515. doi: 10.1016/s0008-6215(03)00197-6

Jin, Y., Zhang, L., Zhang, M., Chen, L., Cheung, P., Oi, V., et al. (2003b). Antitumor activities of heteropolysaccharides of Poria cocos mycelia from different strains and culture media. Carbohydr. Res. 338 (14), 1517-1521. doi: 10.1016/s0008-6215(03)00198-8

Jin, J., Zhou, R., Xie, J., Ye, H., Liang, X., Zhong, C., et al. (2019). Insights into Triterpene Acids in Fermented Mycelia of Edible Fungus Poria cocos by a Comparative Study. Molecules 24 (7), 1331. doi: 10.3390/molecules24071331

Kanayama, H., Adachi, N., and Togami, M. (1983). A new antitumor polysaccharide from the mycelia of Poria cocos wolf. Chem. Pharm. Bull. (Tokyo) 31 (3), 1115-1118. doi: 10.1248/cpb.31.1115

Kanayama, H., Adachi, N., Fukai, Y., Takeuchi, I., and Togami, M. (1986). Studies on the antitumor-active polysaccharides from the mycelia of Poria cocos Wolf. II. Structural analysis of antitumor polysaccharide H11. Yakugaku Zasshi 106 (3), 206-211.

Ke, R., Lin, S., Chen, Y., Ji, C., and Shu, Q. (2010). Analysis of chemical composition of polysaccharides from Poria cocos Wolf and its anti-tumor activity by NMR spectroscopy. Carbohydr. Polymer. 80 (2010), 31-34. doi: 10.1016/j.carbpol.2009.10.063

Kim, K., Moon, E., Kim, S., Choi, S., and Lee, K. (2012). Lignan constituents of Tilia amurensis and their biological evaluation on antitumor and antiinflammatory activities. Food Chem. Toxicol. Int. J. Published Br. Ind. Biol. Res. Assoc. 50 (10), 3680-3686. doi: 10.1016/j.fct.2012.07.014

Kobira, S., Atsumi, T., Kakiuchi, N., and Mikage, M. (2012). Difference in cultivation characteristics and genetic polymorphism between Chinese and Japanese strains of Wolfiporia cocos Ryvarden et Gilbertson (Poria cocos Wolf). J. Nat. Med. 66 (3), 493-499. doi: 10.1007/s11418-011-0612-0

Lai, K., Lu, M., Du, Y., EI-Shaly, M., Wu, T., Hsu, Y., et al. (2016). Cytotoxic Lanostanoids from Poria cocos. J. Natural Prod 79 (11), 2805-2813. doi: 10.1021/acs.jnatprod.6b00575

Lee, K., and Jeon, Y. (2003). Polysaccharide isolated from Poria cocos sclerotium induces NF-kappaB/Rel activation and iNOS expression in murine macrophages. Int. Immunopharmacol. 3 (10-11), 1353-1362. doi: 10.1016/ S1567-5769(03)00113-9

Lee, K., You, H., Jeong, H., Kang, J., Kim, H., Rhee, S., et al. (2004). Polysaccharide isolated from Poria cocos sclerotium induces NF-kappaB/ Rel activation and iNOS expression through the activation of p38 kinase in murine macrophages. Int. Immunopharmacol. 4 (8), 1029-1038. doi: 10.1016/j.intimp.2004.03.014

Lee, J., Lee, Y., Shin, J., Nam, J., Nah, S., Kim, S., et al. (2009). Effects of triterpenoids from Poria cocos Wolf on the serotonin type $3 \mathrm{~A}$ receptormediated ion current in Xenopus oocytes. Eur. J. Pharmacol. 615 (1-3), 2732. doi: 10.1016/j.ejphar.2009.04.063

Lee, S., Lee, S., Moon, E., Park, H., Park, H., and Kim, K. (2017). Bioactivity-guided isolation of anti-inflammatory triterpenoids from the sclerotia of Poria cocos using LPS-stimulated Raw264.7 cells. Bioorg. Chem. 70, 94-99. doi: 10.1016/ j.bioorg.2016.11.012
Lee, S., Choi, E., Yang, S., Ryoo, R., Moon, E., Kim, K., et al. (2018a). Bioactive compounds from sclerotia extract of Poria cocos that control adipocyte and osteoblast differentiation. Bioorg. Chem. 81, 27-34. doi: 10.1016/j.bioorg. 2018.07.031

Lee, S., Lee, S., Roh, H., Song, S., Ryoo, R., Pang, C., et al. (2018b). Cytotoxic Constituents from the Sclerotia of against Human Lung Adenocarcinoma Cells by Inducing Mitochondrial Apoptosis. Cells 7 (9), 116. doi: 10.3390/cells7090116

Li, G., Hse, C., and Qin, T. (2012). Preparation and characterization of novolak phenol formaldehyde resin from liquefied brown-rotted wood. J. Appl. Polymer. Sci. 125 (4), 3142-3147. doi: 10.1002/app.36476

Li, S., Zhang, J., Li, S., Liu, C., Liu, S., and Liu, Z. (2017). Extraction and separation of lactate dehydrogenase inhibitors from Poria cocos (Schw.) Wolf based on a hyphenated technique and in vitro methods. J. Sep Sci. 40 (8), 1773-1783. doi: 10.1002/jssc. 201700054

Li, X., Ma, L., and Zhang, L. (2019). Molecular basis for Poria cocos mushroom polysaccharide used as an antitumor drug in China. Prog. Mol. Biol. Transl. Sci. 163, 263-296. doi: 10.1016/bs.pmbts.2019.02.011

Li, H., Bu, X., Li, K., and Wu, D. (2019). Production of a novel Poria cocos immunomodulatory protein in Pichia pastoris: cloning, expression, purification and activities assays. World J. Microbiol. Biotechnol. 35 (2), 27. doi: 10.1007/s11274-019-2602-4

Lin, Z., and Zhang, H. (2004). Anti-tumor and immunoregulatory activities of Ganoderma lucidum and its possible mechanisms. Acta Pharmacol. Sin. 25 (11), 1387-1395.

Lin, Y., Zhang, L., Chen, L., Jin, Y., Zeng, F., Jin, J., et al. (2004). Molecular mass and antitumor activities of sulfated derivatives of alpha-glucan from Poria cocos mycelia. Int. J. Biol. Macromol. 34 (5), 289-294. doi: 10.1016/ j.ijbiomac.2004.08.001

Lindner, D., and Banik, M. (2008). Molecular phylogeny of Laetiporus and other brown rot polypore genera in North America. Mycologia 100 (3), 417-430. doi: $10.3852 / 07-124 \mathrm{r} 2$

Liu, X., Yu, X., Xu, X., Zhang, X., and Zhang, X. (2018). The protective effects of Poria cocos-derived polysaccharide CMP33 against IBD in mice and its molecular mechanism. Food Funct. 9 (11), 5936-5949. doi: 10.1039/c8fo01604f

Liu, X., Wang, X., Xu, X., and Zhang, X. (2019). Purification, antitumor and antiinflammation activities of an alkali-soluble and carboxymethyl polysaccharide CMP33 from Poria cocos. Int. J. Biol. Macromol. 127, 39-47. doi: 10.1016/ j.ijbiomac.2019.01.029

Lu, M., Cheng, J., Lin, C., and Chang, C. (2010). Purification, structural elucidation, and anti-inflammatory effect of a water-soluble 1,6-branched 1,3- $\alpha$-d-galactan from cultured mycelia of Poria cocos. Food Chem. 118 (2), 349-356. doi: 10.1016/j.foodchem2009.04.126

Lu, C., Ma, J., and Cai, D. (2017). Pachymic acid inhibits the tumorigenicity of gastric cancer cells by the mitochondrial pathway. Anti-cancer Drugs 28 (2), 170-179. doi: 10.1097/CAD.0000000000000449

Lu, C., Cai, D., and Ma, J. (2018). Pachymic Acid Sensitizes Gastric Cancer Cells to Radiation Therapy by Upregulating Bax through Hypoxia. Am. J. Chin. Med. 46 (4), 875-890. doi: 10.1142/S0192415X18500465

Lv, C., Li, Q., Zhang, Y., Sui, Z., He, B., Xu, H., et al. (2013). A UFLC-MS/MS method with a switching ionization mode for simultaneous quantitation of polygalaxanthone III, four ginsenosides and tumulosic acid in rat plasma: application to a comparative pharmacokinetic study in normal and Alzheimer's disease rats. J. Mass Spectrom 48 (8), 904-913. doi: 10.1002/jms.3230

Ma, L., Chen, H., Dong, P., and Lu, X. (2013). Anti-inflammatory and anticancer activities of extracts and compounds from the mushroom Inonotus obliquus. Food Chem. 139 (1-4), 503-508. doi: 10.1016/j.foodchem.2013.01.030

Miao, G., Han, J., Zhang, J., Wu, Y., and Tong, G. (2019). Targeting Pyruvate Kinase M2 and Hexokinase II, Pachymic Acid Impairs Glucose Metabolism and Induces Mitochondrial Apoptosis. Biol. Pharm. Bull. 42 (1), 123-129. doi: 10.1248/bpb.b18-00730

Nozaki, K., Hikiami, H., Goto, H., Nakagawa, T., Shibahara, N., and Shimada, Y. (2014). Keishibukuryogan (gui-zhi-fu-ling-wan), a Kampo formula, decreases disease activity and soluble vascular adhesion molecule-1 in patients with rheumatoid arthritis. Evid. Based Complement. Alternat. Med. 3 (3), 359-364. doi: 10.1093/ecam/nel025

Nukaya, H., Yamashiro, H., Fukazawa, H., Ishida, H., and Tsuji, K. (1996). Isolation of inhibitors of TPA-induced mouse ear edema from Hoelen, Poria cocos. Chem. Pharm. Bull. 44 (4), 847-849. doi: 10.1248/cpb.44.847 
Park, Y., Son, I., Kim, B., Lyu, Y., Moon, H., and Kang, H. (2009). Poria cocos water extract (PCW) protects PC12 neuronal cells from beta-amyloid-induced cell death through antioxidant and antiapoptotic functions. Die Pharmazie 64 (11), 760-764.

Peng, C., Yang, M., Yang, Y., Yu, C., and Wang, C. (2017). Antrodia cinnamomea Prevents Obesity, Dyslipidemia, and the Derived Fatty Liver via Regulating AMPK and SREBP Signaling. Am. J. Chin. Med. 45 (1), 67-83. doi: 10.1142/ s0192415x17500069

Pu, Y., Liu, Z., Tian, H., and Bao, Y. (2019). The immunomodulatory effect of Poria cocos polysaccharides is mediated by the $\mathrm{Ca}(2+) / \mathrm{PKC} / \mathrm{p} 38 / \mathrm{NF}-\mathrm{kappaB}$ signaling pathway in macrophages. Int. Immunopharmacol. 72, 252-257. doi: 10.1016/j.intimp.2019.04.017

$\mathrm{Pu}$, Y., Liu, Z., Tian, H., and Bao, Y. (2019). The immunomodulatory effect of Poria cocos polysaccharides is mediated by the $\mathrm{Ca} / \mathrm{PKC} / \mathrm{p} 38 / \mathrm{NF}-\mathrm{\kappa B}$ signaling pathway in macrophages. Int. Immunopharmacol. 72, 252-257. doi: 10.1016/ j.intimp.2019.04.017

Qian, Q., Zhou, N., Qi, P., Zhang, Y., Mu, X., Shi, X., et al. (2018). A UHPLCQTOF-MS/MS method for the simultaneous determination of eight triterpene compounds from Poria cocos (Schw.) Wolf extract in rat plasma: Application to a comparative pharmacokinetic study. J. Chromatogr. B., 1102-1103, 34-44. doi: 10.1016/j.jchromb.2018.10.011

Ríos, J. (2011). Chemical constituents and pharmacological properties of Poria cocos. Planta Med. 77 (7), 681-691. doi: 10.1055/s-0030-1270823

Royal Botanical Gardens at Kew (2020). Species Fungorum. Available at: http:// www.speciesfungorum.org/Names/SynSpecies.asp?RecordID $=107372$.

Shen, A., Wang, T., Huang, M., Liao, C., Chen, S., and Lin, C. (2005). Antioxidant and Antiplatelet Effects of Dang-Gui-Shao-Yao-San on Human Blood Cells. Am. J. Chin. Med. 33 (5), 747-758. doi: 10.1142/S0192415X05003351

Shingu, T., Tai, T., and Akahori, A. (1992). A lanostane triterpenoid from Poria cocos. Phytochemistry 31 (7), 2548-2549. doi: 10.1016/0031-9422(92)83325-S

Song, D., Cao, Z., Tickner, J., Qiu, H., Wang, C., Wang, Z., et al. (2018). Poria cocos polysaccharide attenuates RANKL-induced osteoclastogenesis by suppressing NFATc1 activity and phosphorylation of ERK and STAT3. Arch. Biochem. Biophysics 647, 76-83. doi: 10.1016/j.abb.2018.04.011

Sun, K., and Xia, H. (2018). Pachymic acid inhibits growth and induces cell cycle arrest and apoptosis in gastric cancer SGC-7901 cells. Oncol. Lett. 16 (2), 25172524. doi: 10.3892/ol.2018.8899

Sun, Y. (2014). Biological activities and potential health benefits of polysaccharides from Poria cocos and their derivatives. Int. J. Biol. Macromol. 68, 131-134. doi: 10.1016/j.ijbiomac.2014.04.010

Tai, T., Shingu, T., Kikuchi, T., Tezuka, Y., and Akahori, A. (1995). Triterpenes from the surface layer of Poria cocos. Phytochemistry 39 (5), 1165-1169. doi: 10.1016/0031-9422(95)00110-S

Tang, J., Nie, J., Li, D., Zhu, W., Zhang, S., Ma, F., et al. (2014). Characterization and antioxidant activities of degraded polysaccharides from Poria cocos sclerotium. Carbohydr. Polym. 105, 121-126. doi: 10.1016/j.carbpol.2014.01.049

Tetsuro, S., Takaaki, T., and Akira, A. (1992). A lanostane triterpenoid from Poria cocos. Phytochemistry 31 (7), 2548-2549. doi: 10.1016/0031-9422(92)83325-S

Tian, H., Liu, Z., Pu, Y., and Bao, Y. (2019). Immunomodulatory effects exerted by Poria Cocos polysaccharides via TLR4/TRAF6/NF- $\mathrm{KB}$ signaling in vitro and in vivo. Biomed. Pharmacother. 112, 108709. doi: 10.1016/j.biopha. 2019.108709

Ukiya, M., Akihisa, T., Tokuda, H., Hirano, M., Oshikubo, M., Nobukuni, Y., et al. (2002). Inhibition of tumor-promoting effects by poricoic acids $\mathrm{G}$ and $\mathrm{H}$ and other lanostane-type triterpenes and cytotoxic activity of poricoic acids $\mathrm{A}$ and G from Poria cocos. J. Nat. Prod. 65 (4), 462-465. doi: 10.1021/np0103721

Wang, Y., and Zhang, L. (2006). Chain conformation of carboxymethylated derivatives of $(1 \rightarrow 3)$ - $\beta$-d-glucan from Poria cocos sclerotium. Carbohydr. Polymer. 65 (4), 504-509. doi: 10.1016/j.carbpol.2006.02.014

Wang, Y., Zhang, M., Ruan, D., Shashkov, A. S., Kilcoyne, M., Savage, A. V., et al. (2004a). Chemical components and molecular mass of six polysaccharides isolated from the sclerotium of Poria cocos. Carbohydr. Res. 339 (2), 327-334. doi: 10.1016/j.carres.2003.10.006

Wang, Y., Zhang, L., Li, Y., Hou, X., and Zeng, F. (2004b). Correlation of structure to antitumor activities of five derivatives of a beta-glucan from Poria cocos sclerotium. Carbohydr. Res. 339 (15), 2567-2574. doi: 10.1016/j.carres. 2004.08.003
Wang, Y., Yu, Y., and Mao, J. (2009). Carboxymethylated beta-glucan derived from Poria cocos with biological activities. J. Agric. Food Chem. 57 (22), 1091310915. doi: $10.1021 / \mathrm{jf} 902589 \mathrm{~m}$

Wang, Y., Xu, W., and Chen, Y. (2010). Surface modification on polyurethanes by using bioactive carboxymethylated fungal glucan from Poria cocos. Colloids Surf. B. Biointerf. 81 (2), 629-633. doi: 10.1016/j.colsurfb.2010.08.015

Wang, Y., Liu, S., Yang, Z., Zhu, Y., Wu, Y., Huang, J., et al. (2011). Oxidation of $\beta$ glucan extracted from Poria Cocos and its physiological activities. Carbohydr. Polymer. 85 (4), 798-802. doi: 10.1016/j.carbpol.2011.03.052

Wang, Y., Li, T., Zhao, Y., Zhang, J., and Liu, H. (2012a). Contents of some metabolites in the peel and flesh of the medicinal mushroom Wolfiporia cocos (F.A. Wolf) Ryvarden et Gilb. (higher Basidiomycetes). Int. J. Med. Mushrooms 14 (1), 79-83. doi: 10.1615/intjmedmushr.v14.i1.80

Wang, Y., Mo, Q., Li, Z., Lai, H., Lou, J., Liu, S., et al. (2012b). Effects of degree of carboxymethylation on physicochemical and biological properties of pachyman. Int. J. Biol. Macromol. 51 (5), 1052-1056. doi: 10.1016/j.ijbiomac.2012.08.022

Wang, Y., Zhang, J., Zhao, Y., Li, T., Shen, T., Li, J., et al. (2013). Mycology, cultivation, traditional uses, phytochemistry and pharmacology of Wolfiporia cocos (Schwein.) Ryvarden et Gilb.: a review. J. Ethnopharmacol. 147 (2), 265276. doi: 10.1016/j.jep.2013.03.027

Wang, W., Dong, H., Yan, R., Li, H., Li, P., Chen, P., et al. (2015). Comparative study of lanostane-type triterpene acids in different parts of Poria cocos (Schw.) Wolf by UHPLC-Fourier transform MS and UHPLC-triple quadruple MS. J. Pharm. Biomed. Anal. 102, 203-214. doi: 10.1016/j.jpba.2014.09.014

Wang, H., Mukerabigwi, J., Zhang, Y., Han, L., Jiayinaguli, T., Wang, Q., et al. (2015). In vivo immunological activity of carboxymethylated-sulfated $(1 \rightarrow 3)$ $\beta$-D-glucan from sclerotium of Poria cocos. Int. J. Biol. Macromol. 79, 511-517. doi: 10.1016/j.ijbiomac.2015.05.020

Wang, N., Zhang, Y., Wang, X., Huang, X., Fei, Y., Yu, Y., et al. (2016). Antioxidant property of water-soluble polysaccharides from Poria cocos Wolf using different extraction methods. Int. J. Biol. Macromol. 83, 103-110. doi: 10.1016/j.ijbiomac.2015.11.032

Wang, M., Chen, D., Wang, M., Chen, H., Chen, L., Liu, D., et al. (2017). Poricoic acid ZA, a novel RAS inhibitor, attenuates tubulo-interstitial fibrosis and podocyte injury by inhibiting TGF-beta/Smad signaling pathway. Phytomedicine 36, 243-253. doi: 10.1016/j.phymed.2017.10.008

Wang, C., Yang, S., Gao, L., Wang, L., and Cao, L. (2018). Carboxymethyl pachyman (CMP) reduces intestinal mucositis and regulates the intestinal microflora in 5-fluorouracil-treated CT26 tumour-bearing mice. Food Funct. 9 (5), 2695-2704. doi: 10.1039/c7fo01886j

Wang, M., Chen, D., Chen, L., Liu, D., Zhao, H., Zhang, Z., et al. (2018). Novel RAS Inhibitors Poricoic Acid ZG and Poricoic Acid ZH Attenuate Renal Fibrosis via a Wnt/beta-Catenin Pathway and Targeted Phosphorylation of smad3 Signaling 66, 8, 1828-1842. doi: 10.1021/acs.jafc.8b00099

Wang, J., Wang, A., He, H., She, X., He, Y., Li, S., et al. (2019a). Trametenolic acid $\mathrm{B}$ protects against cerebral ischemia and reperfusion injury through modulation of microRNA-10a and PI3K/Akt/mTOR signaling pathways. Biomed. Pharmacother. 112, 108692. doi: 10.1016/j.biopha.2019.108692

Wang, J., Bie, M., Zhou, W., Xie, B., and Sun, Z. (2019b). Interaction between carboxymethyl pachyman and lotus seedpod oligomeric procyanidins with superior synergistic antibacterial activity. Carbohydr. Polym. 212, 11-20. doi: 10.1016/j.carbpol.2019.02.030

Wang, Q., Zuo, Z., Huang, H., and Wang, Y. (2020). Comparison and quantitative analysis of wild and cultivated Macrohyporia cocos using attenuated total refection-Fourier transform infrared spectroscopy combined with ultra-fast liquid chromatography. Spectrochim. Acta Part A. Mol. Biomol. Spectrosc. 226, 117633. doi: 10.1016/j.saa.2019.117633

Wen, H., Wu, Z., Hu, H., Wu, Y., Yang, G., Lu, J., et al. (2018). The anti-tumor effect of pachymic acid on osteosarcoma cells by inducing PTEN and Caspase 3/7dependent apoptosis. J. Nat. Med. 72 (1), 57-63. doi: 10.1007/s11418-017-1117-2

$\mathrm{Wu}, \mathrm{S}$., Ng, L., and Lin, C. (2004). Antioxidant activities of some common ingredients of traditional chinese medicine, Angelica sinensis, Lycium barbarum and Poria cocos. Phytother. Res. 18 (12), 1008-1012. doi: 10.1002/ptr.1617

Wu, L., Wang, K., Mao, X., Liang, W., Chen, W., Li, S., et al. (2016). Screening and Analysis of the Potential Bioactive Components of Poria cocos (Schw.) Wolf by HPLC and HPLC-MS(n) with the Aid of Chemometrics. Molecules 21 (2), 227. doi: 10.3390/molecules 21020227 
Wu, Y., Li, S., Li, H., Zhao, C., Ma, H., Zhao, X., et al. (2016). Effect of a polysaccharide from Poria cocos on humoral response in mice immunized by H1N1 influenza and HBsAg vaccines. Int. J. Biol. Macromol. 91, 248-257. doi: 10.1016/j.ijbiomac.2016.05.046

Wu, K., Fan, J., Huang, X., Wu, X., and Guo, C. (2018). Hepatoprotective effects exerted by Poria Cocos polysaccharides against acetaminophen-induced liver injury in mice. Int. J. Biol. Macromol. 114, 137-142. doi: 10.1016/j.ijbiomac.2018.03.107

Wu, K., Guo, C., Yang, B., Wu, X., and Wang, W. (2019). Antihepatotoxic benefits of Poria cocos polysaccharides on acetaminophen-lesioned livers in vivo and in vitro. J. Cell. Biochem. 120 (5), 7482-7488. doi: 10.1002/jcb.28022

Yang, C., Zhang, S., Liu, W., Zhang, Z., and Liu, J. (2010). Two New Triterpenes from the Surface Layer of Poria cocos. Helv. Chim. Acta 92 (4), 660-667. doi: 10.1002/hlca.200800360

Yang, L., Qin, B., Feng, S., Liu, S., and Song, X. (2010). A new triterpenoid from traditional Chinese medicine Poria cocos. J. Chem. Res. 34 (10), 553-554. doi: 10.3184/030823410x12853461890093

Yang, L., Tang, J., Chen, J., Peng, A., Wang, Q., Rao, L., et al. (2019). Transcriptome analysis of three cultivars of Poria cocos reveals genes related to the biosynthesis of polysaccharides. J. Asian Nat. Prod. Res. 21 (5), 462-475. doi: 10.1080/10286020.2018.1494159

Yasukawa, K., Kaminaga, T., Kitanaka, S., Tai, T., Nunoura, Y., Natori, S., et al. (1998). 3 beta-p-hydroxybenzoyldehydrotumulosic acid from Poria cocos, and its anti-inflammatory effect. Phytochemistry 48 (8), 1357-1360. doi: 10.1016/ s0031-9422(97)01063-7

Yuan, T., Zhao, Y., Zhang, J., and Wang, Y. (2018). Application of variable selection in the origin discrimination of Wolfiporia cocos (F.A. Wolf) Ryvarden \& Gilb. based on near infrared spectroscopy. Sci. Rep. 8 (1), 89. doi: 10.1038/s41598-017-18458-9

Zan, J., Shen, C., Zhang, L., and Liu, Y. (2017). Effect of Poria cocos hydroethanolic extract on treating adriamycin-induced rat model of nephrotic syndrome. Chin. J. Integr. Med. 23 (12), 916-922. doi: 10.1007/s11655-016-2643-6

Zeng, H., Liu, Q., Yu, J., Jiang, X., Wu, Z., Wang, M., et al. (2015). One-step separation of nine structural analogues from Poria cocos (Schw.) Wolf. via tandem high-speed counter-current chromatography. J. Chromatography B. Analyt. Technol. Biomed. Life Sci. 1004, 10-16. doi: 10.1016/j.jchromb.2015.09.017

Zhang, L., Chen, L., Xu, X., Zeng, F., and Cheung, P. (2005). Effect of molecular mass on antitumor activity of heteropolysaccharide from Poria cocos. Biosci. Biotechnol. Biochem. 69 (3), 631-634. doi: 10.1271/bbb.69.631

Zhang, M., Chiu, L., Cheung, P., and Ooi, V. (2006). Growth-inhibitory effects of a b-glucan from the mycelium of Poria cocos on human breast carcinoma MCF7 cells_cell-cycle arrest and apoptosis induction. Oncol. Rep. 15 (3), 637-643.

Zhang, N., Chen, H., Ma, L., and Zhang, Y. (2013). Physical modifications of polysaccharide from Inonotus obliquus and the antioxidant properties. Int. J. Biol. Macromol. 54, 209-215. doi: 10.1016/j.ijbiomac.2012.12.030

Zhang, Y., Zhang, Y., Li, X., Feng, X., Jian, W., and Li, R. (2017). Antitumor activity of the pachymic acid in nasopharyngeal carcinoma cells.
Ultrastruct. Pathol. 41 (3), 245-251. doi: 10.1080/01913123.2017. 1296522

Zhang, W., Chen, L., Peng, L., Zhao, J., and Duan, J. (2018). Antidepressant and immunosuppressive activities of two polysaccharides from Poria cocos (Schw.) Wolf. Int. J. Biol. Macromol. 120 (Pt B), 1696-1704. doi: 10.1016/j.ijbiomac. 2018.09.171

Zhang, W., Cheng, N., Wang, Y., Zheng, X., Zhao, Y., Wang, H., et al. (2019). Adjuvant activity of PCP-II, a polysaccharide from Poria cocos, on a whole killed rabies vaccine. Virus Res. 270, 197638. doi: 10.1016/j.virusres.2019.06.001

Zhang, G., Wang, H., Xie, W., Wang, Q., Wang, X., Wang, C., et al. (2019). Comparison of triterpene compounds of four botanical parts from Poria cocos (Schw.) wolf using simultaneous qualitative and quantitative method and metabolomics approach. Food Res. Int. (Ottawa Ont) 121, 666-677. doi: 10.1016/j.foodres.2018.12.036

Zhao, Y., Li, H., Feng, Y., Bai, X., and Lin, R. (2013). Urinary metabonomic study of the surface layer of Poria cocos as an effective treatment for chronic renal injury in rats. J. Ethnopharmacol. 148 (2), 403-410. doi: 10.1016/j.jep.2013.04.018

Zheng, Y., and Yang, X. (2008a). Absorption of triterpenoid compounds from Indian bread (Poria cocos) across human intestinal epithelial (Caco-2) cells in vitro. Zhongguo Zhong Yao Za Zhi 33 (13), 1596-1601.

Zheng, Y., and Yang, X. (2008b). Two new lanostane triterpenoids from Poria cocos. J. Asian Natural Prod Res. 10 (3-4), 323-328. doi: 10.1080/1028602080 1892250

Zhou, L., Zhang, Y., Gapter, L., Ling, H., Agarwal, R., and Ng, K. (2008). Cytotoxic and anti-oxidant activities of lanostane-type triterpenes isolated from Poria cocos. Chem. Pharm. Bull. 56 (10), 1459-1462. doi: 10.1248/cpb.56.1459

Zhu, L., Xu, J., Wang, R., Li, H., Tan, Y., Chen, H., et al. (2018). Poria cocosCorrelation between Quality and Geographical Origins of Revealed by Qualitative Fingerprint Profiling and Quantitative Determination of Triterpenoid Acids. Mol. (Basel Switzerland) 23 (9), 2200. doi: 10.3390/molecules 23092200

Zhu, L., Xu, J., Zhang, S., Wang, R., Huang, Q., Chen, H., et al. (2018). Qualitatively and quantitatively comparing secondary metabolites in three medicinal parts derived from Poria cocos (Schw.) Wolf using UHPLC-QTOFMS/MS-based chemical profiling. J. Pharm. Biomed. Anal. 150, 278-286. doi: 10.1016/j.jpba.2017.11.066

Conflict of Interest: The authors declare that the research was conducted in the absence of any commercial or financial relationships that could be construed as a potential conflict of interest.

Copyright (c) $2020 \mathrm{Nie}$, Chao, Zhang, Jia, Zhou and Zhu. This is an open-access article distributed under the terms of the Creative Commons Attribution License (CC BY). The use, distribution or reproduction in other forums is permitted, provided the original author(s) and the copyright owner(s) are credited and that the original publication in this journal is cited, in accordance with accepted academic practice. No use, distribution or reproduction is permitted which does not comply with these terms. 